\title{
Energetics and Dynamics of Naphthalene Polyaminic Derivatives. Influence of Structural Design in the Balance Static vs Dynamic Excimer Formation
}

\author{
J. Seixas de Melo* and J. Pina \\ Department of Chemistry (CQC), University of Coimbra, 3004-535 Coimbra, Portugal \\ F. Pina, C. Lodeiro, A. J. Parola, and J. C. Lima \\ Departamento de Química, Centro de Química Fina e Biotecnologia - REQUIMTE, \\ Faculdade de Ciências e Tecnologia, Universidade Nova de Lisboa, Quinta da Torre, \\ 2829-516 Monte de Caparica, Portugal
}

\author{
M. Teresa Albelda, M. Paz Clares, and Enrique Garcia-España* \\ Departament de Química Inorgànica, Facultat de Química, Universitat de València, Burjassot, Spain \\ Conxa Soriano \\ Departament de Química Orgànica, Facultat de Farmàcia, Universitat de València, Burjassot, Spain \\ Received: July 23, 2003; In Final Form: October 16, 2003
}

\begin{abstract}
Two new fluorescent macrocyclic structures bearing two naphthalene $(\mathrm{Np})$ units at both ends of a cyclic polyaminic chain were investigated with potentiometric, fluorescence (steady-state and time-resolved) and laser flash photolysis techniques. The fluorescence emission studies show the presence of an excimer species whose formation depends on the protonation state of the polyamine chains implying the existence of a bending movement (occurring in both the ground and in the first singlet excited state), which allows the two naphthalene units to approach and interact. For comparison purposes, one bis-chromophoric compound containing a rigid chain (piperazine unit) was also investigated. Its emission spectra shows a unique band decaying single exponentially thus showing that no excimer is formed. With the two new ligands, excimer formation occurs in all situations even at very acidic $\mathrm{pH}$ values when the protonation of the polyamine bridges is extensive. Coexistence of ground-state dimers with dynamic excimers was established based on steady-state and timeresolved fluorescence data. The energetics of excimer formation and dissociation were determined in ethanol and water. Different methods of decay analysis (independent decay deconvolution, global analysis and excimer deconvolution with monomer) were used to extract the kinetic (rate constants for excimer formation, dissociation, and decay) and thermodynamic parameters. In ethanol and acidified ethanol:water mixtures, an additional short decay time was found to exist and assigned to a dimer, whose presence is assumed to be responsible by the decrease in activation energy for excimer formation in this solvent. The results are globally discussed in terms of the small architectural differences that can induce significant changes in the photophysical behavior of the three studied compounds.
\end{abstract}

\section{Introduction}

Molecules exhibiting molecular movements in response to an applied stimulus have promoted intensive interest in the past decades, see for example the recent refs $1-4$ and references therein. Nowadays, the development of supramolecular chemistry as an advanced interdisciplinary field has led to several interests in photochemistry including a systematic research on the design and synthesis of molecular systems in which (i) changes in fluorescence can signal analyte complexation ${ }^{5-8}$ and (ii) molecular movements are induced by light or other external stimuli. ${ }^{3,9-13}$ In the first case, the design of such molecules relies on the use of a guest binding site (receptor) and a fluorophore (a photon interaction site), connected through a spacer unit. In the second situation, light or other factors such as the hydrogen

* To whom correspondence should be addressed. E-mail: sseixas@ci.uc.pt (J.S.d.M.); enrique.garcia-es@uv.es (E.G.E.). ion concentration of the media can induce conformational changes in molecules leading to new and nonexisting entities previous to the external stimuli.

As a part of our effort to discover new molecules able to perform movements and to signal metal cations and anions, we have in the past years ${ }^{10,11,14-23}$ exhaustively tested different compounds having as common characteristics a polyamine recognition unit and a fluorescent signaling or interactive unit, which were able either to recognize anions/cations ${ }^{12-14,16,18,24}$ or be the driving force of molecular movements. ${ }^{10,22,23}$

The present work aims at achieving this strategy with a single structure. However, for purposes of clarity of this work, sensing of cations will not be discussed here and will be released in a separated work. To do so, we have prepared the novel compounds L1 and L2 in which ethylamino naphthyl arms have been appended to the central nitrogens of the bridges of 2:2 cyclophanes containing diethylenetriamine arms and 


\section{SCHEME 1}

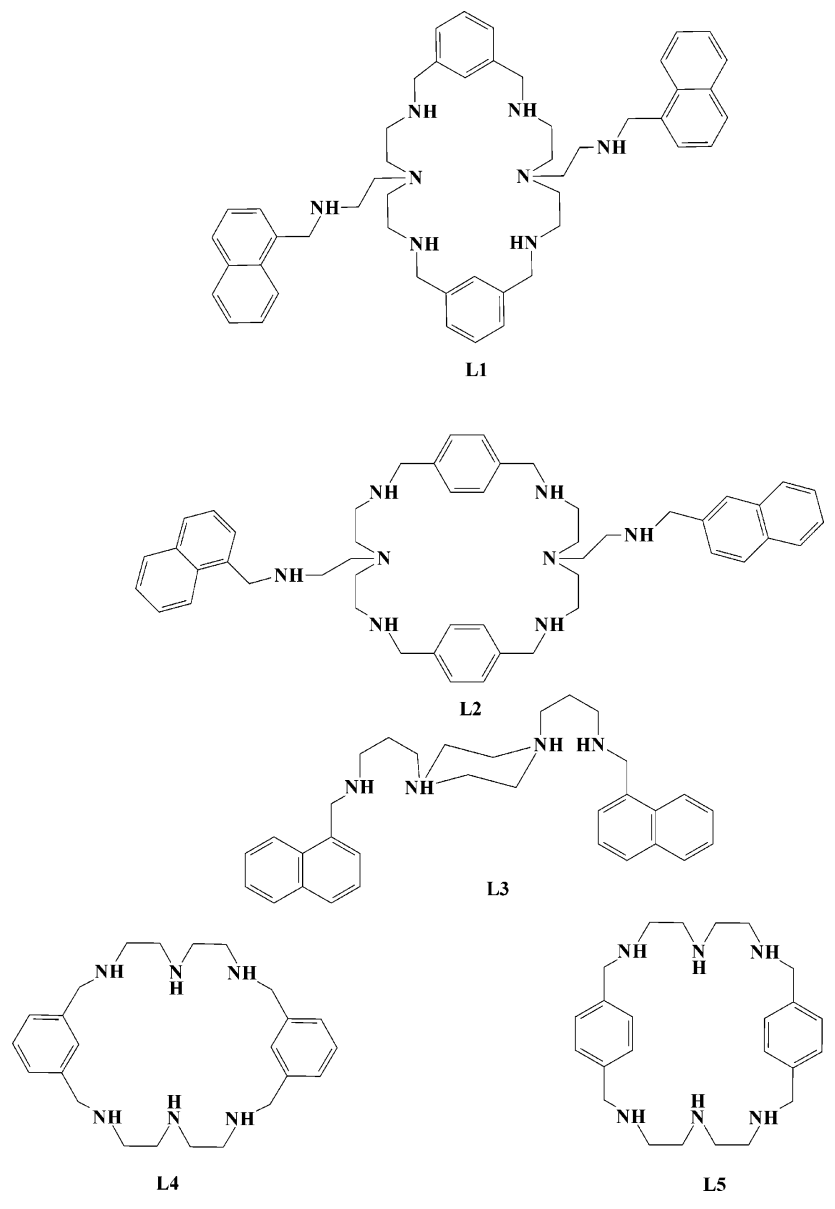

$m$-phenylene or $p$-phenylene spacers (Scheme 1 ). The study was undertaken to answer the following questions concerning these fluorescent sensors. How does $\mathrm{pH}$ affect (i) the fluorescence of L1 and L2; (ii) excimer formation, i.e., can $\mathrm{pH}$ be used to control this light-induced elementar molecular movement; (iii) the existence of preformed dimers in the ground state; and (iv) how does intersystem crossing contribute to the deactivation of the fluorescent state?

It will be shown that excimer formation occurs in both the ground state and first singlet excited state of the two compounds. The degree of ground-state association vs excited-state association is qualitatively obtained and the relative stability of the excimers formed is discussed.

\section{Experimental Section}

Synthesis. The synthesis of the receptors $\mathbf{L} \mathbf{1}$ and $\mathbf{L} 2$ was achieved by a 2:2 dipodal condensation in ethanol of the tripodal polyamine tren monofunctionalized with a methyl naphthalene group ${ }^{9}$ and the corresponding benzene dicarbaldehyde (Scheme 2 ). The formed imine was reduced with sodium borohydride to give the desired compounds with high overall yield. The precursor tren derivative was prepared following the procedure we have used previously for the preparation of different monochromophoric compounds in which the polyamine in slight excess is reacted with 1-naphthalenaldehyde.

Naphthalen-1-ylmethyl-[2-(20-\{2-[(naphthalen-1-ylmethyl)amino]-ethyl $\}-3,6,9,17,20,23$-hexaaza-tricyclo[23.3.1.111,15]triaconta-1(29),11(30),12,14,25,27-hexaen-6-yl)-ethyl]amine Octahydrochloride Trihydrate $\left(\mathrm{L1} \cdot 8 \mathrm{HCl} \cdot 3 \mathrm{H}_{2} \mathrm{O}\right) . N^{1}$ (2-Amino-ethyl)- $N^{1}$ - $\{2$-[(naphthalen-1-ylmethyl)-amino]-ethyl $\}$ ethane-1,2-diamine (1.01 $\mathrm{g}, 3.53 \mathrm{mmol})$ and benzene-1,3-

\section{SCHEME 2}
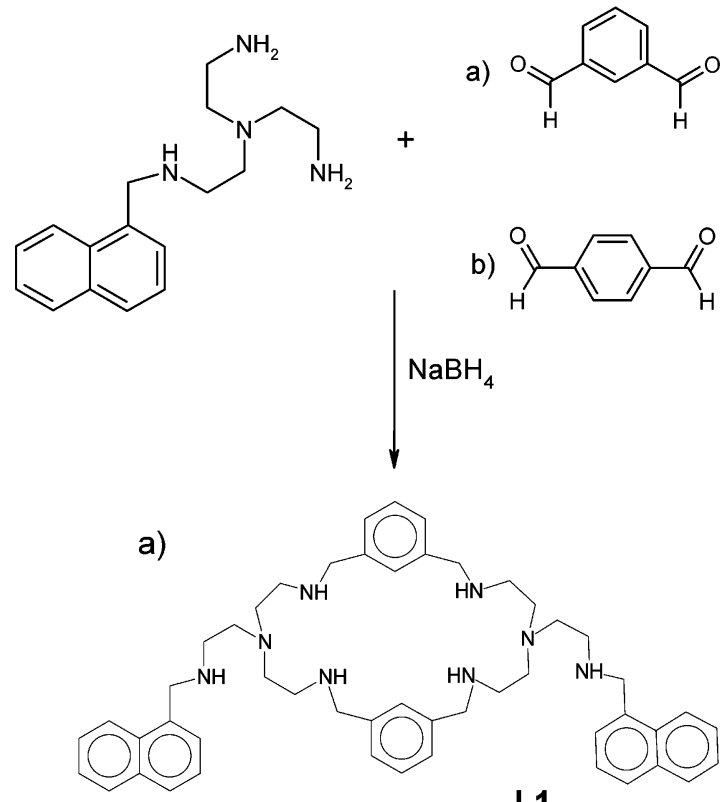

L1

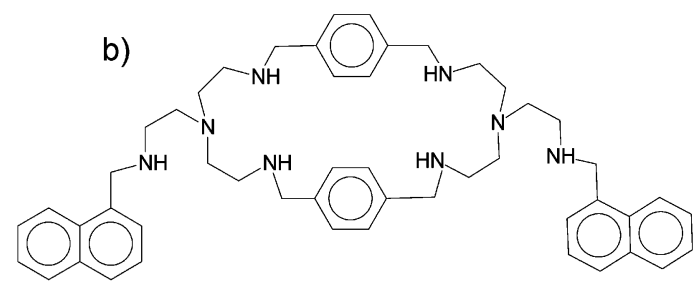

L2

dicarbaldehyde $(0.488 \mathrm{~g}, 3.53 \mathrm{mmol})$ were stirred for $3 \mathrm{~h}$ in 75 $\mathrm{mL}$ of EtOH. Sodium borohydride (1.073 g, $0.0282 \mathrm{mmol}$ ) was then added, and the resulting solution was stirred for $1 \mathrm{~h}$. The ethanol was removed at reduced pressure. The resulting residue was treated with water, and the difunctionalized amine was repeatedly extracted with dichloromethane $(3 \times 30 \mathrm{~mL})$. The organic phase was dried with anhydrous sodium sulfate, and the solvent was evaporated to yield the free amine, which was dissolved in ethanol and precipitated as its hydrochloride salt. $32 \%$ yield; $777.5 \mathrm{~m} / \mathrm{z} ; \mathrm{mp}=232-235{ }^{\circ} \mathrm{C}$; solvent $\mathrm{D}_{2} \mathrm{O}, \delta_{\mathrm{H}}$ (ppm): $2.80(\mathrm{t}, J=5 \mathrm{~Hz}, 8 \mathrm{H}), 2.84-2.87(\mathrm{~m}, 4 \mathrm{H}), 3.17(\mathrm{t}, J$ $=5 \mathrm{~Hz}, 8 \mathrm{H}), 3.26(\mathrm{t}, J=4 \mathrm{~Hz}, 4 \mathrm{H}), 4.23(\mathrm{~s}, 8 \mathrm{H}), 4.69(\mathrm{~s}, 4 \mathrm{H})$, $7.48-7.63(\mathrm{~m}, 16 \mathrm{H}), 7.97(\mathrm{~d}, J=6 \mathrm{~Hz}, 2 \mathrm{H}), 7.98(\mathrm{~d}, J=8$ $\mathrm{Hz}, 2 \mathrm{H}), 8.02(\mathrm{~d}, J=8 \mathrm{~Hz}, 2 \mathrm{H}) . \delta_{\mathrm{C}}(\mathrm{ppm}): 44.9,48.3,49.6$, 51.3, 122.8, 125.5, 127.0, 127.7, 129.4, 129.6, 130.4, 130.8, 131.4, 131.6, 132.3. Anal. Calcd. for $\mathrm{C}_{50} \mathrm{H}_{78} \mathrm{~N}_{8} \mathrm{Cl}_{8} \mathrm{O}_{3} \mathrm{C} 56.40$, H 6.44, N 10.52. Found C 56.0, H 6.4, N 10.5.

Naphthalen-1-ylmethyl-[2-(19-\{2-[(naphthalen-1-ylmethyl)amino]-ethyl\}-3,6,9,16,19,22-hexaaza-tricyclo[22.2.2.2 $\left.{ }^{11,14}\right]$ triaconta-1(27),11(30),12,14(29),24(28),25-hexaen-6-yl)-ethyl]amine Hexahydrochloride Hexahydrate $\left(\mathrm{L} 2 \cdot 6 \mathrm{HCl} \cdot 6 \mathrm{H}_{2} \mathrm{O}\right)$. The procedure used for the preparation of $\mathbf{L} \mathbf{2}$ was the same as that just described for L1. Yield 37\%; $777.5 \mathrm{~m} / \mathrm{z} ; \mathrm{mp}=203-$ $205{ }^{\circ} \mathrm{C}$; solvent $\mathrm{D}_{2} \mathrm{O}, \delta_{\mathrm{H}}(\mathrm{ppm}): 2.92-2.96(\mathrm{~m}, 8 \mathrm{H}), 3.19(\mathrm{t}, J$ $=6 \mathrm{~Hz}, 8 \mathrm{H}), 3.28(\mathrm{t}, J=6 \mathrm{~Hz}, 8 \mathrm{H}), 4.34(\mathrm{~s}, 8 \mathrm{H}), 4.72(\mathrm{~s}, 4 \mathrm{H})$, $7.42(\mathrm{~d}, 4 \mathrm{H}), 7.51-7.66(\mathrm{~m}, 10 \mathrm{H}), 7.89-7.97(\mathrm{~m}, 6 \mathrm{H}), 8.07$ $(\mathrm{d}, J=8 \mathrm{~Hz}, 2 \mathrm{H}) . \delta_{\mathrm{C}}(\mathrm{ppm}): 44.3,44.4,48.0,48.1,49.1,51.1$, $122.8,125.5,127.0,127.7,129.4,129.6,130.4,138.0,131.4$, 131.6, 132.3. Anal. Calcd. for $\mathrm{C}_{50} \mathrm{H}_{82} \mathrm{~N}_{8} \mathrm{Cl}_{6} \mathrm{O}_{6} \mathrm{C}, 56.20, \mathrm{H}$ 6.73, N 10.48. Found C 56.6, H 7.0, N 10.2.

Potentiometric Masurements. The potentiometric titrations were carried out at $298.1 \pm 0.1 \mathrm{~K}$ using $\mathrm{NaCl} 0.15 \mathrm{~mol} \mathrm{dm}^{-3}$ 
as the supporting electrolyte. The experimental procedure (buret, potentiometer, cell, stirrer, microcomputer, etc.) has been fully described elsewhere. ${ }^{25}$ The acquisition of the emf data was performed with the computer program PASAT. ${ }^{26}$ The reference electrode was an $\mathrm{Ag} / \mathrm{AgCl}$ electrode in saturated $\mathrm{KCl}$ solution. The glass electrode was calibrated as a hydrogen-ion concentration probe by titration of previously standardized amounts of $\mathrm{HCl}$ with $\mathrm{CO}_{2}$-free $\mathrm{NaOH}$ solutions and determining the equivalent point by the Gran's method, ${ }^{27,28}$ which gives the standard potential, $E^{\circ \prime}$, and the ionic product of water $\left(\mathrm{p} K_{\mathrm{w}}=\right.$ 13.73(1)).

The computer program HYPERQUAD was used to calculate the protonation and stability constants. ${ }^{29}$ The $\mathrm{pH}$ range investigated was 2.0-11.0. The different titration curves for each ligand were treated either as a single set or as separated curves without significant variations in the values of the stability constants. Finally, the sets of data were merged together and treated simultaneously to give the final stability constants.

Spectrophotometric and Spectrofluorimetric Measurements. The solvents used were of spectroscopic or equivalent grade. Ethanol was previously dried over $\mathrm{CaO}$ and then distilled. Water was twice distilled and passed through a Millipore apparatus. All aqueous solutions were prepared in $0.15 \mathrm{~mol}$ $\mathrm{dm}^{-3} \mathrm{NaCl}$. The measured $\mathrm{pH}$ values were obtained with a Crison micropH 2000, and adjustments of the hydrogenionic concentration of the solutions were made with diluted $\mathrm{HCl}$ and $\mathrm{NaOH}$ solutions.

Absorption and fluorescence spectra were recorded on Shimadzu UV-2100 and Jovin-Yvon Spex Fluorog 3-2.2. spectrometers, respectively. Fluorescence spectra were corrected for the wavelength response of the system. The fluorescence quantum yield of compound $\mathbf{L} \mathbf{3}$ was determined using naphthalene $\left(\phi_{\mathrm{F}}=0.21\right.$ in ethanol $\left.{ }^{30}\right)$ as the standard. The fluorescence quantum yields for compounds $\mathbf{L} \mathbf{1}$ and $\mathbf{L} \mathbf{2}$ were measured in aqueous solution for different values of $\mathrm{pH}$, using the previous obtained value for $\mathbf{L 3}$ compound, $\phi_{\mathrm{F}}\left(\mathrm{H}_{2} \mathrm{O}, \mathrm{pH}=4.5\right)=$ $0.32,{ }^{22,23}$ as reference.

For obtaining the fluorescence quantum efficiency for the excimer $\left(\phi_{\mathrm{F}}^{\mathrm{E}}\right)$ occurring with the $\mathbf{L} \mathbf{1}$ and $\mathbf{L} 2$ compounds, the standard used was $\mathbf{L 3}$ and the total fluorescence quantum yield, $\phi_{\mathrm{F}}^{\mathrm{T}}$, was obtained with the use of equation:

$$
\phi_{\mathrm{F}}^{\mathrm{E}}=\frac{\phi_{\mathrm{F}}^{\mathrm{Ap}}}{1-\frac{\phi_{\mathrm{M}}^{\mathrm{Ap}}}{\phi_{\mathrm{F}}^{\mathrm{M}}}}
$$

where the apparent fluorescence yields, $\phi_{\mathrm{F}}^{\mathrm{Ap}}$ and $\phi_{\mathrm{M}}^{\mathrm{Ap}}$, result from the integrated areas under the exciplex and monomer bands, respectively, with $\phi_{\mathrm{F}}^{\mathrm{T}}=\phi_{\mathrm{Exc}}^{\mathrm{Ap}}+\phi_{\mathrm{M}}^{\mathrm{Ap}}$, and $\phi_{\mathrm{F}}^{\mathrm{M}}$ is the fluorescence quantum yield of the reference (L3) compound considered as the monomeric one.

The $I_{\mathrm{E}} / I_{\mathrm{M}}$ ratio results from the decomposed area under the monomer and excimer bands. The general procedure to obtain those values consisted in matching the emission spectra of $\mathbf{L 3}$ in water with the monomer band of compounds $\mathbf{L 1}$ and L2, after which the match of the relative intensities and vibronic band progression is almost identical for both the L3 and L1 and $\mathbf{L} \mathbf{2}$ compounds. The resulting differential spectrum is the excimer band. In this procedure, the $x x^{\prime}$ scale must be used in energetic units.

Fluorescence decays were measured using a home-built TCSPC apparatus with a $\mathrm{D}_{2} / \mathrm{N}_{2}$ filled IBH 5000 coaxial flashlamp as excitation source, excitation and emission Jobin-
Yvon monochromator, Philips XP2020Q photomultiplier, and Canberra instruments TAC and MCA. ${ }^{31}$ The fluorescence decays were analyzed using the method of modulating functions implemented by Striker. ${ }^{32}$

Triplet-singlet difference absorption spectra and yields were obtained using an Applied Photophysics laser flash photolysis equipment pumped by a Nd:YAG laser (Spectra Physics) with excitation wavelength $355 \mathrm{~nm}$ as described elsewhere. ${ }^{33}$ Firstorder kinetics was observed for the decay of the lowest triplet state. The transient spectra $(250-500 \mathrm{~nm})$ were obtained by monitoring the optical density change at 5-10 nm intervals, averaging at least 10 decays at each wavelength.

In all cases, the signal was assigned to a triplet state because (i) it was quenched by oxygen (quenching constant by oxygen, $k_{\mathrm{ox}}=1.5-2.5 \times 10^{9} \mathrm{M}^{-1} \mathrm{~s}^{-1}$ ), (ii) it decayed by first-order kinetics with microsecond lifetimes, (iii) in these experiments other possible transients such as radical ions were not produced on photolysis.

The triplet molar absorption coefficients of L1 in water were determined by the singlet depletion technique, according to the well-known relationship: ${ }^{34}$

$$
\epsilon_{\mathrm{T}}=\frac{\epsilon_{\mathrm{S}} \cdot \Delta \mathrm{OD}_{\mathrm{T}}}{\Delta \mathrm{OD}_{\mathrm{S}}}
$$

where both $\triangle \mathrm{OD}_{\mathrm{S}}$ and $\triangle \mathrm{OD}_{\mathrm{T}}$ are obtained from the triplet transient absorption spectra and triplet formation quantum yields derived from these and actinometry with benzophenone. The $\phi_{\mathrm{T}}$ value was obtained by comparing the $\Delta \mathrm{OD}$ at $525 \mathrm{~nm}$ of a benzene solution of benzophenone (the standard) and of a water solution of the compound (optically matched at the laser wavelength) using the equation ${ }^{35}$

$$
\phi_{\mathrm{T}}^{\mathrm{L} 1}=\frac{\epsilon_{\mathrm{TT}}^{\text {Benzophenone }}}{\epsilon_{\mathrm{TT}}^{\mathrm{L} 1}} \frac{\Delta \mathrm{OD}_{\max }^{\mathrm{L} 1}}{\Delta \mathrm{OD}_{\max }^{\text {Benzoph. }}} \phi_{\mathrm{T}}^{\text {Benzophenone }}
$$

$\epsilon_{\mathrm{TT}}^{\text {Benzophenone }}=7200 \mathrm{M}^{-1} \mathrm{~cm}^{-1}$ and $\phi_{\mathrm{T}}^{\text {Benzophenone }}=1.34$

\section{Results and Discussion}

Acid-Base Behavior. Table 1 collects the stepwise stability constants of compounds L1 and L2 determined in $0.15 \mathrm{~mol} \mathrm{dm}^{-3}$ $\mathrm{NaCl}$ at $298.1 \mathrm{~K}$. For the sake of comparison, the stepwise protonation constants for the nonfunctionalized cyclophanes L4 and $\mathbf{L 5}$ (Scheme 1) taken from the literature are also included in Table $1 .^{36,37}$

The compounds $\mathbf{L} \mathbf{1}$ and $\mathbf{L} \mathbf{2}$ present close sequences of the protonation constants. Both compounds present, in aqueous solution, six protonation steps in the $\mathrm{pH}$ range $2-11$. The decrease in the basicity of every step is rather constant indicating that the different protonation steps affect to nitrogen atoms placed far apart between them. Therefore, these protonations should occur on the secondary amino groups of the bridges linking the benzene rings and on the secondary amino groups of the dangling arms and a net protonation of the tertiary nitrogens in the middle of the arms would not occur.

A comparison of $\mathbf{L 1}$ and $\mathbf{L 2}$ with the nonfunctionalized macrocycles L4 and L5 shows that although the protonation constants of the first four steps are similar those for the fifth and sixth protonation steps are much lower for L4 and L5. Again, this reflects the higher electrostatic repulsions produced in protonation steps that involve amino groups separated each other by ethylenic chains.

Steady-State Fluorescence. pH Dependence. The absorption spectra of compounds $\mathbf{L 1}-\mathbf{L 3}$ (figure not shown) display the 
TABLE 1: Logarithms of the Stepwise Protonation Constants for L1 and L2 Determined at $298.1 \mathrm{~K}$ in $0.15 \mathrm{~mol}$ $\mathbf{d m}^{-3} \mathrm{NaCl}^{a}$

\begin{tabular}{lcccc}
\hline \multicolumn{1}{c}{ reaction $^{b}$} & L1 $^{c}$ & L2 $^{c}$ & L4 $^{d}$ & L5 $^{d}$ \\
\hline $\mathrm{L}+\mathrm{H} \rightleftarrows \mathrm{HL}$ & $9.51(2)$ & $9.80(2)$ & 9.51 & 9.54 \\
$\mathrm{HL}+\mathrm{H} \rightleftarrows \mathrm{H}_{2} \mathrm{~L}$ & $8.48(2)$ & $7.97(4)$ & 8.77 & 8.76 \\
$\mathrm{H}_{2} \mathrm{~L}+\mathrm{H} \rightleftarrows \mathrm{H}_{3} \mathrm{~L}$ & $8.02(1)$ & $7.67(4)$ & 7.97 & 8.16 \\
$\mathrm{H}_{3} \mathrm{~L}+\mathrm{H} \rightleftarrows \mathrm{H}_{4} \mathrm{~L}$ & $7.30(3)$ & $6.92(5)$ & 7.09 & 7.26 \\
$\mathrm{H}_{4} \mathrm{~L}+\mathrm{H} \rightleftarrows \mathrm{H}_{5} \mathrm{~L}$ & $6.86(3)$ & $6.61(4)$ & 3.70 & 3.30 \\
$\mathrm{H}_{5} \mathrm{~L}+\mathrm{H} \rightleftarrows \mathrm{H}_{6} \mathrm{~L}$ & $6.09(5)$ & $5.41(9)$ & 3.27 & 2.50 \\
$\log \beta^{\mathrm{e}}$ & 46.3 & 44.4 & 40.4 &
\end{tabular}

${ }^{a}$ The constants for compounds $\mathbf{L} \mathbf{4}$ and $\mathbf{L 5}$ have been taken from refs 36 and 37. ${ }^{b}$ Charges omitted for clarity. ${ }^{c}$ Figures in parentheses are standard deviations in the last significant figure. ${ }^{d}$ Taken from ref. 36, $37 \log \beta=\Sigma \log K_{\mathrm{HjL}}$.

$$
v\left(\mathrm{~cm}^{-1}\right)
$$$$
20000 \quad 25000 \quad 30000
$$
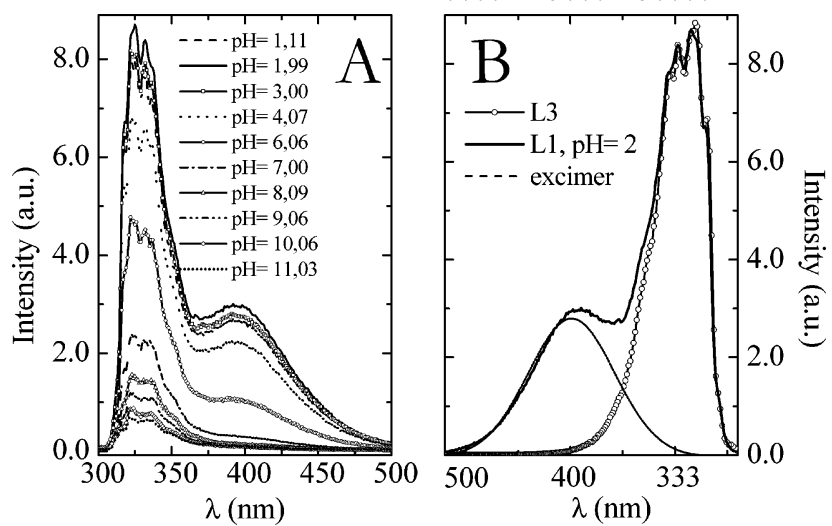

Figure 1. Fluorescence spectra of (A) compound L1 at different hydrogen ion concentrations and (B) compound $\mathbf{L 1}$ at $\mathrm{pH}=2$, compound $\mathbf{L 3}$ and the isolated excimer spectra (resulting from decomposition of $\mathbf{L 1}$ with $\mathbf{L} \mathbf{3}$ spectra).

characteristic band of naphthalene with very little dependence on the wavelength maxima upon the degree of protonation $(\mathrm{pH}$ of the media), as was found with analogous compounds. ${ }^{10,22,23}$

Figure 1 shows the dependence of the (A) fluorescence spectra of compound L1 with $\mathrm{pH}$ and (B) the spectra of compound $\mathbf{L} \mathbf{1}$ at $\mathrm{pH}=2$, together with compound $\mathbf{L} \mathbf{3}$ and the isolated excimer spectra (resulting from decomposition of $\mathbf{L 1}$ with $\mathbf{L 3}$ spectra).

The $\mathbf{L} \mathbf{2}$ emission spectrum is identical to that of compound L1. In the two cases, the characteristic bands, resulting from the monomer (320 nm maxima) and excimer (400 $\mathrm{nm}$ maxima) emission, are present, whereas with $\mathbf{L 3}$, the excimer band is absent. ${ }^{12,22,23}$ The protonation state of the compound largely influences its fluorescence emission spectra. As a consequence of different hydrogen ion concentration of the media, changes in the fluorescence intensity (not in shape) are due to the fact that the deprotonation of the amines allows them to quench the excited fluorophore by electron transfer. ${ }^{38}$ Therefore, the gradual decrease of the total fluorescence emission, with the $\mathrm{pH}$ increase, is a consequence of the competitive quenching (electron transfer), promoted by the unprotonated amine groups. ${ }^{38}$ The decomposed spectra also denote that at the monomer emission wavelength maxima ( $\cong 323 \mathrm{~nm}$ ) there is still some excimer emission contribution. The reciprocal is also found to occur at the excimer emission maximum ( $\cong 395 \mathrm{~nm})$ where some monomer emission exists. This will be of special relevance in the analysis of the time-resolved data (see below). In fact, even if we choose $420 \mathrm{~nm}$ as the emission wavelength, for collection of the excimer decays, where in principle no monomer should
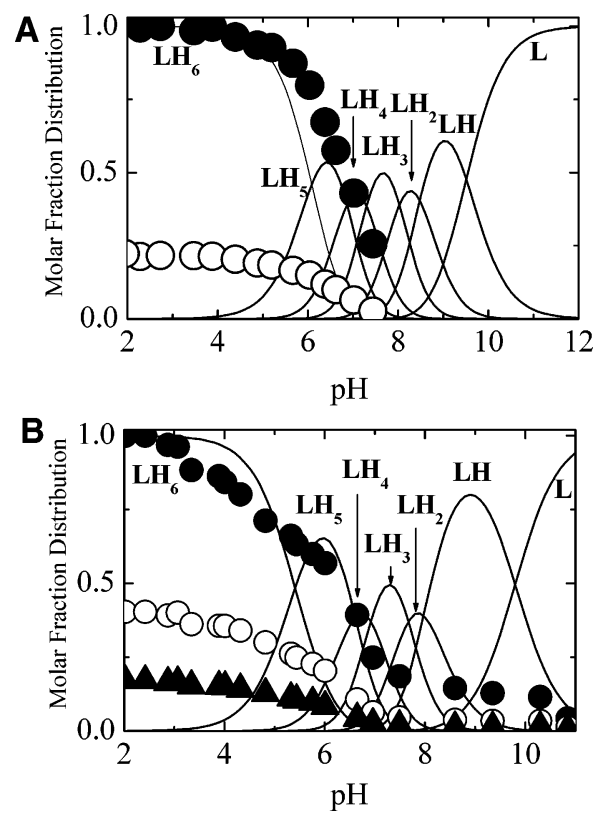

Figure 2. Steady-state fluorescence emission titration curves of (A) $\mathbf{L 1}$ and (B) $\mathbf{L} 2$ obtained with $\lambda_{\mathrm{exc}}=280 \mathrm{~nm} \lambda_{\mathrm{em}}=324,325 \mathrm{~nm}$ (closed circles); 392, $400 \mathrm{~nm}$ (open circles); and $440 \mathrm{~nm}$ (closed triangles) at $T=20^{\circ} \mathrm{C}$.

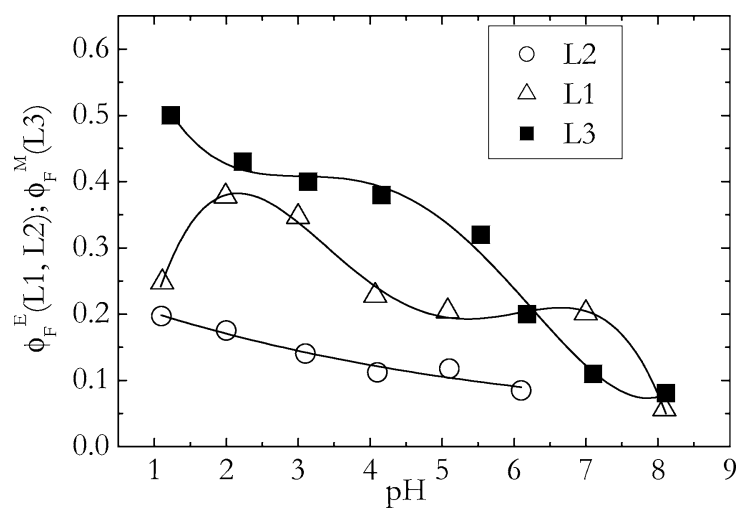

Figure 3. Plots of the excimer fluorescence quantum yield for compounds $\mathbf{L} 1$ (open triangles) and $\mathbf{L} 2$ (open circles) and monomer fluorescence quantum yield for compound $\mathbf{L 3}$ (closed squares) at $T=$ $20^{\circ} \mathrm{C}$, as a function of the $\mathrm{pH}$. The lines are just meant to be guidelines for the eye.

emit (see Figure 1B), the use of slits with $10 \mathrm{~nm}$ band-pass cannot avoid some small, but remaining, monomer emission at that wavelength.

Figure 2 presents the titration curve resulting from the fluorescence emission titration curves together with the mole fraction distribution of the different protonated species (obtained by potentiometry). Such representation can be further used to obtain the relative fluorescence emission quantum yields of all of the emissive species.

The absolute values for the excimer fluorescence quantum yield $\left(\phi_{\mathrm{F}}^{\mathrm{E}}\right)$ dependence with the $\mathrm{pH}$, obtained with eq 1 , are shown in Figure 3, together with the fluorescence quantum yield for the $\mathbf{L} \mathbf{3}$ compound. For the two compounds the $\phi_{\mathrm{F}}^{\mathrm{E}}$ values decrease with the decrease of the hydrogen ion concentration of the media. The same occurs with the absolute monomer fluorescence quantum yield (taken as the value for compound L3). However, the observation of Figure 3 reveals that while $\phi_{\mathrm{F}}^{\mathrm{M}}$ decreases more than $500 \%$ (from 0.5 to 0.1 ) the changes occurring with $\phi_{\mathrm{F}}^{\mathrm{E}}$ for compounds $\mathbf{L} \mathbf{1}$ and especially $\mathbf{L} \mathbf{2}$ are much less significant. The significance of this observation lies 


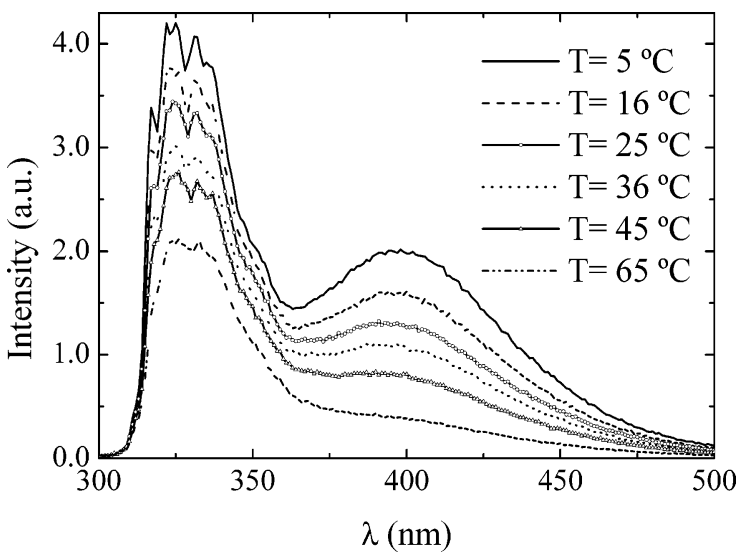

Figure 4. Temperature dependence of the fluorescence emission spectra for compound $\mathbf{L 1}$ at $\mathrm{pH}=2$.

in the fact that the monomer fluorescence is much more susceptible to be quenched by the unprotonated amine groups than excimer emission is. This means that between the two competitive pathways, excimer formation and electron quenching by the unprotonated amine groups, the former is much less significant. Because both deactivation pathways are strongly dependent on the $\mathrm{pH}$, it is likely that the strong decrease in the excimer emission results from the large predominance of the electron quenching, rather than in the reduction on the degree of movements (to induce excimer formation), to the total emission of the compounds. Also in concommitance with this is the fact that the deprotonation decreases the rigidity of the polyaminic chain thus favoring the movement for excimer formation. Because the excimer formation decreases with the $\mathrm{pH}$, this again gives emphasis to the predominance of the electron quenching effect in the fluorescence of compounds $\mathbf{L} \mathbf{1}$ and $\mathbf{L} 2$.

Temperature Dependence. The steady-state temperature dependence of compound $\mathbf{L} \mathbf{1}$ and $\mathbf{L 2}$, presented in Figure 4, reveals a decrease of the total fluorescence emission intensity with the increase in temperature. This is a well-known occurring phenomenon in aromatic-like molecules, resulting from the gradual predominance of the radiationless relative to the radiative processes. However, when the ratio of the two emissive bands is plotted as a function of the reciprocal of the temperature, two different regions appear giving rise to two different behaviors.

Arrhenius Plots of $\ln \boldsymbol{I}_{\mathrm{E}} / \boldsymbol{I}_{\mathrm{M}}$ vs $\mathbf{1} / \boldsymbol{T}$. The variation of the ratio of the excimer to monomer bands $\left(I_{\mathrm{E}} / I_{\mathrm{M}}\right)$ with the temperature is described, within the framework of the Birks' kinetic scheme, ${ }^{39}$ by eq 4

$$
\frac{I_{\mathrm{E}}}{I_{\mathrm{M}}}=\frac{k_{\mathrm{F}}^{\mathrm{E}}}{k_{\mathrm{F}}^{\mathrm{M}}} \frac{k_{\mathrm{a}}}{k_{\mathrm{d}}+k_{\mathrm{E}}}
$$

where $k_{\mathrm{F}}^{\mathrm{E}}$ and $k_{\mathrm{F}}^{\mathrm{M}}$ are the excimer and monomer radiative rate constants, $k_{\mathrm{a}}$ and $k_{\mathrm{d}}$ are respectively the excimer formation and dissociation rate constants, and $k_{\mathrm{E}}$ is the excimer rate constant. In general, when the temperature is increased, the excimer dissociation rate constant, $k_{\mathrm{d}}$, grows in a faster manner than $k_{\mathrm{E}}$ does, and reaches a limit where $k_{\mathrm{d}} \gg k_{\mathrm{E}}$ (high-temperature limit, HTL), which leads to simplification of eq 4

$$
\frac{I_{\mathrm{E}}}{I_{\mathrm{M}}}=\frac{k_{\mathrm{F}}^{\mathrm{E}}}{k_{\mathrm{F}}^{\mathrm{M}}} \frac{k_{\mathrm{a}}}{k_{\mathrm{d}}}
$$
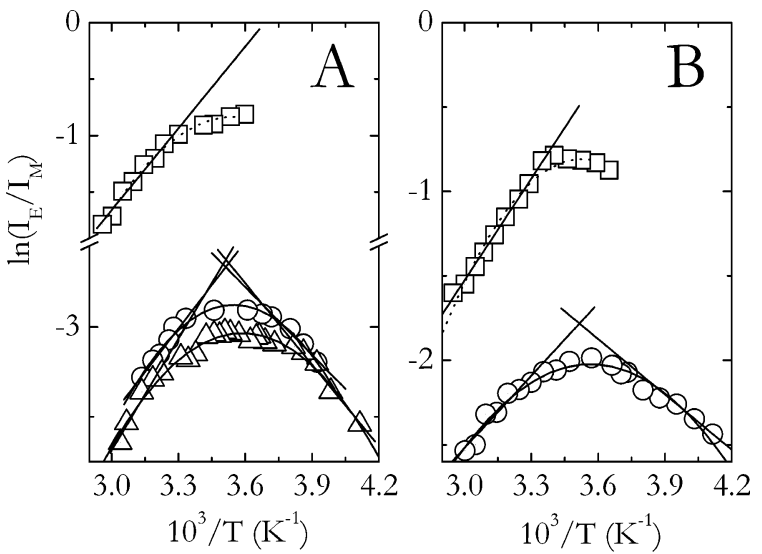

Figure 5. Arrhenius plots for the ratio $I_{\mathrm{E}} / I_{\mathrm{M}}$ obtained in ethanol $(\mathrm{O})$, acidified ethanol $(\triangle)$, and water ( $\square$ ) for (A) compound L1 and (B) compound L2. The parabolic lines accompanying the experimental data are just meant to be guidelines for the eye.

This means that, within this limit, the ratio $k_{\mathrm{a}} / k_{\mathrm{d}}$ reflects the equilibrium constant for the excimer formation reaction. The opposite consideration, i.e., $k_{\mathrm{d}} \ll k_{\mathrm{E}}$ (low-temperature limit, LTL) leads to simplification of eq 4 to eq $6^{10}$

$$
\frac{I_{\mathrm{E}}}{I_{\mathrm{M}}}=\frac{k_{\mathrm{F}}^{\mathrm{E}}}{k_{\mathrm{F}}^{\mathrm{M}}} \tau_{\mathrm{E}} k_{\mathrm{a}}
$$

In the great majority of the situations, the rate constants, $k_{\mathrm{F}}^{\mathrm{E}}$ and $k_{\mathrm{F}}^{\mathrm{M}}$, and the excimer lifetime, $\tau_{\mathrm{E}}$, are temperature independent. The resulting Arrhenius plots of $\ln \left(I_{\mathrm{E}} / I_{\mathrm{M}}\right)$ vs the reciprocal of the temperature, known as Stevens-Ban plots, ${ }^{40}$ will yield two straight lines whose slopes define, in the LTL, the excimer formation activation energy $\left(E_{\mathrm{a}}\right)(\text { eq } 7)^{10}$

$$
\frac{d \ln \left(\frac{I_{\mathrm{E}}}{I_{\mathrm{M}}}\right)}{d\left(\frac{1}{T}\right)}=-\frac{E_{\mathrm{a}}}{R}
$$

and, in the HTL, the binding energy $(\Delta H)$ for the excimer complex (eq 8)

$$
\frac{d \ln \left(\frac{I_{\mathrm{E}}}{I_{\mathrm{M}}}\right)}{d\left(\frac{1}{T}\right)}=-\frac{\left(E_{\mathrm{a}}-E_{\mathrm{d}}\right)}{R}=-\frac{\Delta H}{R}
$$

The resulting Stevens - Ban plots ${ }^{40}$ of the $\ln \left(I_{\mathrm{E}} / I_{\mathrm{M}}\right)$ vs the reciprocal of the absolute temperatures for $\mathbf{L} \mathbf{1}$ and $\mathbf{L} \mathbf{2}$ compounds are presented in Figure 5. In ethanol, the excimer-tomonomer intensity ratio $\left(I_{\mathrm{E}} / I_{\mathrm{M}}\right)$ reaches its maximum value at $T \cong 11-12{ }^{\circ} \mathrm{C}(\mathbf{L} \mathbf{1}$ and $\mathbf{L 2})$. Again in ethanol as solvent, from the low- (LTL) and high-temperature (HTL) regimes, it is possible to extract respectively the activation energy for the excimer formation, $E_{\mathrm{a}}$, and the enthalpy of excimer formation $(\Delta H)$, see Table 2. However, in water, the line defining the LTL is absent. Reasons for this can simply be attributed to the fact that, at the lowest temperature possible to undergo the study of the system in water $\left(\cong 4^{\circ} \mathrm{C}\right)$, the LTL is not reached, or instead it could be the evidence for ground-state dimer association (see Time-Resolved Fluorescence Data section). As expected (see Table 2), the enthalpy or the binding energy for excimer formation is always negative thus showing that the process is thermodynamically favorable. 
TABLE 2: Thermodynamic Parameters for Compounds L1 and L2 Obtained, in Different Solvents, from the Stevens-Ban Plots in Figure 5

\begin{tabular}{lcc}
\hline compound (solvent) & $E_{\mathrm{a}}\left(\mathrm{kJ} \mathrm{mol}^{-1}\right)$ & $\Delta H\left(\mathrm{~kJ} \mathrm{~mol}^{-1}\right)$ \\
\hline & $\mathbf{L 1}$ & \\
(water, $\mathrm{pH}=2)$ & $29^{a}$ & -20 \\
ethanol & 11 & -13 \\
ethanol:HCl & 13 & -17 \\
& $\mathbf{L 2}$ & \\
water $(\mathrm{pH}=2)$ & $34^{a}$ & -17 \\
ethanol & 9 & -12
\end{tabular}

${ }^{a}$ From time-resolved data.

Arrhenius Plots of $\ln I_{\mathrm{E}} / I_{\mathrm{M}}$ vs $1 / T$ in the Presence of Ground-State Dimers. When considering monomer-to-excimer formation, the presence of ground-state dimers (GSD), sometimes also known as dark dimers, ${ }^{41}$ leads to severe departure from the conventional kinetic formalisms. Frequently, visual inspection of the fluorescence excitation spectra collected in the monomer and excimer regions gives additional information concerning the presence of GSD. In fact, differences in the excitation spectra, when collected in the monomer and excimer emission regions, are frequently used as evidence for associative ground-state dimers. ${ }^{42}$ These differences can consist in a more or less pronounced shift in the wavelength maximum of the two spectra, ${ }^{42-44}$ differences in the peak-to-valley ratio relative to the $(0,1)$ transition observed in the monomer and excimer, and also to a more pronounced broadening of the $S_{0} \rightarrow S_{1}$ absorption band (which leads to a more pronounced absorption in the red part of the spectra). All of these differences, as well as those observed in the absorption spectra, have present the idea that a more or less intense absorption band, relative to ground-state aggregates, is overlapped by the intense monomer band. In the present case, there is a nonsignificant shift in the wavelength maxima or peak-to-valley ratio relative to the more intense transition. However, as can be seen in Figure 6, those are not fully overlapped in the red-edge region of the spectra. This is valid for both $\mathbf{L} \mathbf{1}$ and $\mathbf{L} \mathbf{2}$ compounds. Even this small difference implies that any kinetic model, to fully equate the system, should include the existence of GSD. The weight of these GSD, to the overall fluorescence, can be determined a posteriori, from the analysis of the data made with the complete model.

As said above, when ground-state dimers exist, the validity of the Birks' kinetic scheme should be questioned, and thus, a new kinetic scheme must be taken into consideration. In this new kinetic scheme, the fractions of light exciting the groundstate monomer species $(1-\alpha)$ and the ground-state excimer species $(\alpha)$, are considered, see Scheme 3 , and as a consequence of this, new equations are derived. ${ }^{45}$

According to this new scheme, the steady-state variation of the ratio of the excimer to monomer bands $\left(I_{\mathrm{E}} / I_{\mathrm{M}}\right)$ with the temperature is now described, ${ }^{45}$ by eq 9

$$
\frac{I_{\mathrm{E}}}{I_{\mathrm{M}}}=\frac{k_{\mathrm{F}}^{\mathrm{E}}}{k_{\mathrm{F}}^{\mathrm{M}}} \frac{\left(\alpha k_{\mathrm{M}}+k_{\mathrm{a}}\right)}{k_{\mathrm{d}}+(1-\alpha) k_{\mathrm{E}}}
$$

where $k_{\mathrm{F}}^{\mathrm{E}}, k_{\mathrm{F}}^{\mathrm{M}}, k_{\mathrm{a}}$, and $k_{\mathrm{d}}$ have the same meaning as in eq 4 . The expressions for the HTL and LTL regimes are consequently also different, leading in the first case to $\left(k_{\mathrm{d}} \gg(1-\alpha) k_{\mathrm{E}}\right)$ eq 10

$$
\frac{I_{\mathrm{E}}}{I_{\mathrm{M}}}=\frac{k_{\mathrm{F}}^{\mathrm{E}}}{k_{\mathrm{F}}^{\mathrm{M}}} \frac{\alpha k_{\mathrm{M}}+k_{\mathrm{a}}}{k_{\mathrm{d}}}
$$

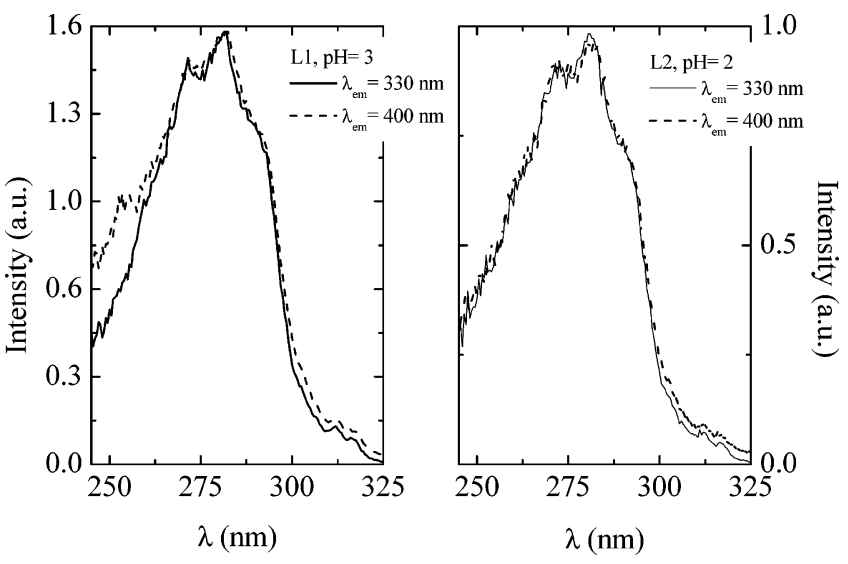

Figure 6. Fluorescence excitation spectra of compounds $\mathbf{L 1}$ and $\mathbf{L 2}$ in water at acidic $\mathrm{pH}$ values collected in the monomer $\left(\lambda_{\mathrm{em}}=330 \mathrm{~nm}\right)$ and excimer emission regions $\left(\lambda_{\mathrm{em}}=400 \mathrm{~nm}\right)$.

\section{SCHEME 3}

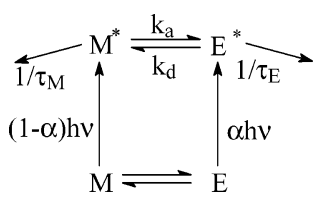

where it can be seen that the excimer binding energy (dependent on the $k_{\mathrm{a}} / k_{\mathrm{d}}$ ratio) is no longer possible to be retrieved due to the presence of the temperature-dependent term $\alpha k_{\mathrm{M}}$. However, because the degree of aggregation decreases with temperature, the increase in temperature will eventually reduce the value of $\alpha k_{\mathrm{M}}$ and in the limit this term will vanish. As a consequence of this, the $\Delta H$ value is possible to be estimated. The $\Delta H$ values, retrieved from intermediate conditions, should therefore be considered as an upper limit because the additional temperaturedependent term (in eq 10) will increase the value for the slope of the $\ln I_{\mathrm{E}} / I_{\mathrm{M}}$ vs $1 / T$ plot in the HTL region.

When the LTL regime $\left(k_{\mathrm{d}} \ll(1-\alpha) k_{\mathrm{E}}\right)$ is considered, eq 9 now reduces to

$$
\frac{I_{\mathrm{E}}}{I_{\mathrm{M}}}=\frac{k_{\mathrm{F}}^{\mathrm{E}}}{k_{\mathrm{F}}^{\mathrm{M}}} \frac{\left(\alpha k_{\mathrm{M}}+k_{\mathrm{a}}\right)}{k_{\mathrm{d}}+(1-\alpha) k_{\mathrm{E}}}
$$

In this situation, the presence of more than one temperaturedependent term (both in the numerator and denominator of eq $11)$ avoids the determination of the activation energy $\left(E_{\mathrm{a}}\right)$ associated with the excimer formation. In fact, in water, the branch of the parabola defining the LTL region (see Figure 5) is not observed; that is, the LTL behavior (decrease of $\ln \left(I_{\mathrm{E}} /\right.$ $I_{\mathrm{M}}$ ) with $1 / T$ after the transition temperature) observed in the case of ethanol is absent in water. After the transition temperature is reached, a plateau is obtained thereon (see Figure 5), which can be due to the dominance of the aggregation dependent term $(\alpha)$. This means that when all of the monomers are preassociated in the ground-state, then $\alpha=1$, and eq 11 becomes meaningless, with the ratio $I_{\mathrm{E}} / I_{\mathrm{M}}$ now being ruled out by the ground-state monomer/dimer equilibrium (Scheme 3). On the other hand, in ethanol, the observed decrease in the $I_{\mathrm{E}} /$ $I_{\mathrm{M}}$ ratio at low temperatures (see Figure 5) translates that (1) the dynamic excimer contribution is still an operative pathway and (2) there is a decrease on the excimer formation rate constant, $k_{\mathrm{a}}$.

As a consequence, from all of the above stated, binding energy values are possible to estimate in water and ethanol from the steady-state data. However, values for the excimer formation 
TABLE 3: Fluorescence Decays Parameters Obtained for Compound $\mathrm{L} 1$ in Water as a Function of the $\mathrm{pH}^{a}$

\begin{tabular}{rcccrrcrccc}
\hline & & & & & & & \multicolumn{5}{c}{$\begin{array}{c}\text { type of } \\
\mathrm{pH}\end{array}$} & $\lambda_{\mathrm{em}}$ & $\tau_{1}$ & $\tau_{2}$ & $\tau_{3}$ & \multicolumn{1}{c}{$a_{\mathrm{i} 1}$} & $a_{\mathrm{i} 2}$ & $a_{\mathrm{i} 3}$ & $\chi^{2}$ & fitting $^{b}$ & $\alpha$ \\
\hline 2 & 320 & 12.3 & 44.3 & & 0.963 & 0.037 & & 1.47 & $\mathrm{G}$ & \\
& 420 & & & & -0.227 & 1.000 & & 1.12 & & 0.77 \\
3 & 320 & 12.3 & 45.5 & & 0.954 & 0.046 & & 1.17 & $\mathrm{G}$ & \\
& 420 & & & & -0.139 & 1.000 & & 0.94 & & 0.86 \\
4 & 320 & 12.7 & 47.4 & & 0.969 & 0.031 & & 1.31 & $\mathrm{G}$ & \\
& 420 & & & & -0.142 & 1.000 & & 1.00 & & 0.86 \\
5 & 320 & 13 & 44 & & 0.993 & 0.007 & & 1.37 & $\mathrm{G}$ & \\
& 420 & & & & -0.257 & 1.000 & & 1.05 & & 0.74 \\
5 & 320 & 15.9 & 45 & 6.8 & 0.589 & 0 & 0.411 & 1.00 & $\mathrm{G}$ & \\
& 420 & & & & 0 & 1.00 & -0.245 & 0.97 & & 0.76 \\
5 & 320 & 14.7 & & 5.5 & 0.682 & & 0.318 & 1.02 & $\mathrm{i}$ & \\
5 & 420 & & 45.2 & 7.7 & & 1.00 & -0.27 & 0.97 & $\mathrm{i}$ & 0.73
\end{tabular}

${ }^{a}$ The data were obtained by global analysis (G) or independent analysis (i) of the decays. Also presented are the chi-squared values for a better judgement of the quality of the fits. Excitation wavelength is $285 \mathrm{~nm}$. Also shown are the fraction of ground-state excitable dimers $(\alpha)$, resulting from the $a_{21}+a_{22}$ (or $a_{23}$ ) sum (see text for more details).

${ }^{b} \mathrm{G}$, global analysis; i, independent analysis.

activation energies are only accessible in ethanol, because, in water, a plateau is reached, with the $\ln \left(I_{\mathrm{E}} / I_{\mathrm{M}}\right)$ vs $1 / T$ steadystate plots. In water, the activation energies, for excimer formation, will consequently be obtained through the analysis of the time-resolved data (see below).

\section{Time-Resolved Fluorescence Data}

pH Dependence. The fluorescence decays for compound L1, obtained at $\mathrm{pH}$ values lower than 4 , are always fitted at the monomer $(320 \mathrm{~nm})$ and excimer $(420 \mathrm{~nm})$ emission regions, with sums of two exponentials. Monomer to excimer excitedstate interconversion is known to be described by a reversible kinetic law mathematically translated by a sum (or difference) of two exponentials, as shown in the classical works of Birks. ${ }^{39}$ At the two emission regions (monomer and excimer), the decay times, $\tau_{1}$ and $\tau_{2}$, are identical, but the same does not happen with the preexponential factors which are related with the excited state concentrations at time zero. At the excimer emission wavelength, a negative preexponential, associated with the faster decay time (rise-time), is generally observed. In fact, at this wavelength, the preexponential factors correspond, respectively, to the formation (rise-time) and decay of the excimer species. If the only route, for excimer formation, were the excited monomer, then the preexponential factors at this wavelength will sum zero. However, in the present case, at the excimer wavelength, the sum of preexponential factors is positive (instead of zero) clearly indicating (1) monomer emission contribution at $420 \mathrm{~nm}$ and/or (2) the existence of preformed dimers in the ground state that directly absorb light $(\alpha>0)$.

From observation of Figure 1, it is clear that there is negligible monomer emission at $420 \mathrm{~nm}$. As a consequence of this, the resulting positive value for the sum of the preexponential values, obtained at that wavelength $(420 \mathrm{~nm})$, are essentially due to the existence of ground state preformed dimers. In Table 3, the data obtained from the fluorescence decays is presented for compound $\mathbf{L 1}$ as a function of $\mathrm{pH}$, and as can be observed, at least up to $\mathrm{pH}=4$, the fraction of preformed dimers (in the sense that this fraction is reflected by the positive sum of preexponentials at $420 \mathrm{~nm}$ ) does not change, as expected, significantly with the $\mathrm{pH}$.

The complete interpretation of the data in Table 3 should be made with the concomitant observation of Figure 2, where the distribution of the different protonated species is presented. From $\mathrm{pH}=2$ until $\mathrm{pH} \cong 4$ it is clear that the only emitting species are the hexaprotonated $\mathrm{LH}_{6}$ and the excimer. This is totally compatible with the double exponential decay found in the decays obtained in that $\mathrm{pH}$ range (Table 3 ). Furthermore, the global analysis of the decays shows that identical decay times in the monomer are recovered at the excimer emission region, which again gives emphasis to the coupled nature of the two involved species: $\mathrm{LH}_{6}$ (monomer) and excimer. At pH 5, there is now the additional presence of the $\mathrm{LH}_{5}$ species, introducing one additional and different decay time into the system. However, this additional species is either uncoupled with the excimer or it possesses an identical decay time value to that of the $\mathrm{LH}_{6}$ species (in this last situation the observed decay time will be an averaged value of the $\mathrm{LH}_{6}$ and $\mathrm{LH}_{5}$ species). This is revealed by the biexponential nature of the excimer decay, with values identical to the shorter $\left(\tau_{1}\right)$ and longer $\left(\tau_{2}\right)$ components obtained with the more acidic solution. The decay time attributed to the $\mathrm{LH}_{6}$ species at $\mathrm{pH} \leq 4\left(\tau_{1} \cong 12 \mathrm{~ns}\right.$, see Table 3$)$ keeps its absolute value at $\mathrm{pH} 5\left(\tau_{1}=13-14.7 \mathrm{~ns}\right.$ depending on the type of analysis), see Table 3 . However, the additional species $\left(\mathrm{LH}_{5}\right)$ is, relative to the $\mathrm{LH}_{6}$ species, strongly quenched $\left(\tau_{3}=\right.$ $5.5-7.7 \mathrm{~ns}$ again dependent on the type of analysis considered), see Table 3.

A further comparison can be established, and this lies in the parallel between the relative percentage of each species, obtained from the steady-state (and potentiometric) data (Figure 2), and those obtained from the amplitudes (preexponential factors) at the monomer by dynamic fluorescence data (Table 3 ). There is a logical assumption, which is to consider that the $\mathrm{LH}_{n}$ species contribution is identical in both the ground-state (from where the potentiometric data is obtained) and the first singlet excited state. In the case of the preexponential factors, those translate the relative concentration of each species in the singlet excited state. From $\mathrm{pH}=2-4$, because the sole contribution is from the $\mathrm{LH}_{6}$ species, the additional component (at the monomer emission wavelength) relates the relative degree of excimer to monomer reversibility. ${ }^{10,22}$ Consequently, there is perfect agreement between the values obtained from three independent techniques. In fact, the potentiometric measurements give rise to a single and multi-protonated species, the steady-state measurements show that there is no appreciable change in the fluorescence intensity up to $\mathrm{pH}=4$ (single species), and finally, the decay time measurements also identify the $\mathrm{LH}_{6}$ species with a lifetime of $\approx 12 \mathrm{~ns}$. At $\mathrm{pH}=5$, the independent analysis of the decay at $320 \mathrm{~nm}$ (monomer) shows that the species decaying with $15 \mathrm{~ns}$ is not giving rise to the excimer (absent at the excimer emission wavelength), and it is therefore uncoupled with the two other decay times.

For compound L2, the data obtained from the fluorescence decays is presented in Figure 7. The plotted data shows that the double exponential fit obtained in all of the $\mathrm{pH}$ ranges studied reflects the clear predominance of the $\mathrm{LH}_{6}$ and $\mathrm{LH}_{5}$ species. Moreover, because the decay time reflects the deactivation routes for the monomer and excimer of $\mathbf{L 2}$, this means that there the two protonated species $\left(\mathrm{LH}_{6}\right.$ and $\left.\mathrm{LH}_{5}\right)$ are no longer distinguishable from each other in terms of fluorescence decay times as it was the case with $\mathbf{L 1}$ at $\mathrm{pH}=5$. It is also worth noting that the amplitude of the longer component at 320 $\mathrm{nm}$ is small, reflecting the low level of reversibility excimerto-monomer. At $420 \mathrm{~nm}$, the preexponential factor associated to the shorter decay time increases with the $\mathrm{pH}$ (from negative to positive values) showing a progressive decrease of the dynamic contribution to excimer formation. 

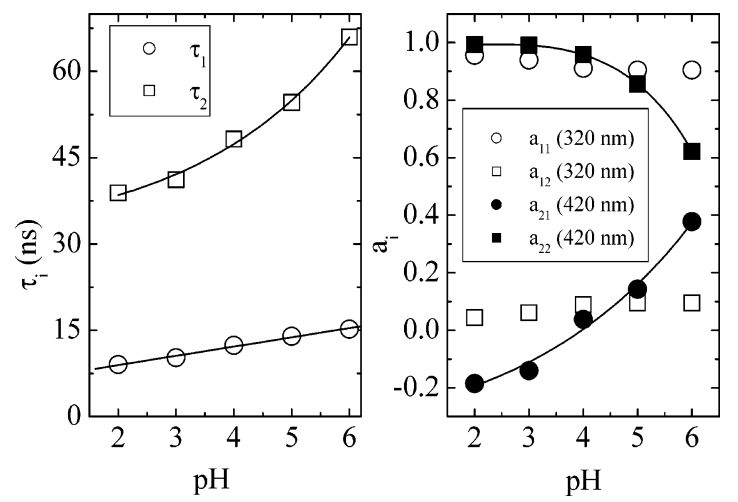

Figure 7. Decay times $\left(\tau_{\mathrm{i}}\right)$ and preexponential $\left(\mathrm{a}_{\mathrm{i}}\right)$ dependence with $\mathrm{pH}$ at $T=20{ }^{\circ} \mathrm{C}$ for compound $\mathbf{L 2}$. The lines are just meant to be guidelines for the eye.

Determination of the Rate Constants and the Use of the Internal Convolution Procedure to Obtain $\boldsymbol{k}_{\mathbf{Y}}$. The determination of the rate constants $k_{\mathrm{a}}, k_{\mathrm{d}}$, and $k_{\mathrm{E}}$ in the classical Birks' kinetic scheme ( $\alpha$ in Scheme 3 equal to 0 ) implies the knowledge of the ratio for preexponential factors (see the Appendix $)$ at the monomer emission $\left(A=a_{12} / a_{11}\right)$ region together with the decay time values $\left(\tau_{1}\right.$ and $\left.\tau_{2}\right)$ and the unquenched lifetime of the monomer, $\tau_{\mathrm{M}}$, which is usually obtained with a model compound thus leading to the following relations:

$$
\begin{gathered}
k_{\mathrm{a}}(\alpha=0)=\frac{A(\alpha=0) \lambda_{2}+\lambda_{1}}{1+A(\alpha=0)}-\frac{1}{\tau_{\mathrm{M}}} \\
k_{\mathrm{d}}(\alpha=0)=\frac{k_{\mathrm{X}}(\alpha=0) k_{\mathrm{Y}}(\alpha=0)-\lambda_{1} \lambda_{2}}{k_{\mathrm{a}}(\alpha=0)}
\end{gathered}
$$

Note that the sum of the preexponential factors at the excimer emission wavelength (equations A.8 and A.9 in the Appendix) leads to $a_{21}+a_{22}=\alpha$, which can be used to estimate the degree of GSD association, see Table 3. However, because in the present situation the amplitude ratio at the monomer emission region (eqs A.6 and A.7 in the Appendix) is dependent on the $\alpha$ value, an alternative treatment is needed in order to obtain information on the kinetic parameters $\left(k_{\mathrm{a}}, k_{\mathrm{d}}\right.$, and $\left.k_{\mathrm{E}}\right)$.

There is no evidence for additional components in the decays supporting different types of excimers. In fact, because the decays fit well with identical decay times at both wavelengths, it looks reasonable to consider that GSD are kinetically indistinguishable from excimers once they reach the excited state; that is, they both decay with the rate constants, $k_{\mathrm{d}}$ and $k_{\mathrm{E}}$. This means that the difference between dynamic and groundstate dimers results in the way the two reach the excited state. The presence of the two routes (dynamic and static) for excimer formation is consequently reflected in the fluorescence decays, by the positive values of the preexponential sum at $420 \mathrm{~nm}$. At excimer emission wavelengths where monomer emission is totally absent, if only dynamic excimer is present, the sum of the preexponential factors should be equal to zero. ${ }^{39}$ Of course, the contribution of preformed dimers, dissociating in the excited state to give an excited monomer, will affect the amplitude of the longest decay time at $320 \mathrm{~nm}$ but not the rate at which it occurs, and if we circumvent the use of amplitudes, it is possible to retrieve information concerning the kinetic parameters.

An alternative way to the above procedure (not using the preexponentials ratio) is based on the evaluation of the $k_{Y}$ value. This can alternatively be obtained from the deconvolution of the excimer decay with the monomer decay (eq 14 where the symbol $\otimes$ means convolution), i.e., the so-called internal convolution procedure ${ }^{46,47}$

$$
\mathrm{I}_{\mathrm{E}}(\mathrm{t})=k_{\mathrm{a}}\left[\mathrm{I}_{\mathrm{M}}(\mathrm{t}) \otimes \mathrm{e}^{-\mathrm{k}_{\mathrm{Y}} \mathrm{t}}\right]
$$

When such analysis is performed, single exponentials decays are obtained (Figure 8A).

With the decay time values, obtained by performing such analysis $\left(\tau_{\mathrm{Y}}=1 / k_{\mathrm{Y}}\right)$, together with the decay time values obtained from the usual deconvolution procedure (Figure $8 \mathrm{~B}$, $\tau_{1}=1 / \lambda_{1}$ and $\left.\tau_{2}=1 / \lambda_{2}\right)$, the $k_{\mathrm{X}}$ values are retrieved from eq 15

$$
k_{\mathrm{X}}=\lambda_{1}+\lambda_{2}-k_{\mathrm{Y}}
$$

The knowledge of the $k_{\mathrm{M}}$ values (obtained from the appropriated model compound, L3) and the use of eqs 16 and 17 leads to the desired $k_{\mathrm{a}}$ and $k_{\mathrm{d}}$ values

$$
\begin{gathered}
k_{\mathrm{a}}=k_{\mathrm{X}}-k_{\mathrm{M}} \\
k_{\mathrm{d}}=\frac{k_{\mathrm{X}} k_{\mathrm{Y}}-\lambda_{1} \lambda_{2}}{k_{\mathrm{a}}}
\end{gathered}
$$

The plot showing the dependence of the $k_{\mathrm{a}}$ and $k_{\mathrm{d}}$ rate constants with $\mathrm{pH}$ is shown in Figure 9.

From Figure 9, it can be seen that the values for $k_{\mathrm{d}}$ and $k_{\mathrm{E}}$, obtained for the two compounds ( $\mathbf{L} 1$ and L2), are quite similar and do not show, within the studied range, any dependence with the hydrogen ion concentration. On the other hand, the $k_{\mathrm{a}}$ values show dependence with the $\mathrm{pH}$ and a displacement between the behavior for the two compounds is observed at acidic $\mathrm{pH}$ values. This differences portents the fact that small structural differences, between the two compounds, can induce a different response to the degree of association, which is reflected in the different values for the $k_{\mathrm{a}}$ rate constant at acidic $\mathrm{pH}$ values.

Applying the identical analysis procedure to the decays obtained, at $\mathrm{pH}=2$, at different temperatures, it is possible to obtain the Arrhenius plots for the excimer formation and dissociation rate constants, see Figure 10.

As the temperature decreases, the percentage of GSD increases (Figure 10b). When the value of $\alpha$ approaches one, the dynamic excimer formation is lost beneath the large contribution of the static formation, as reflected on the loss of linearity of the Arrhenius plots at low temperatures (see Figure 10a). However, at sufficiently high temperatures the dependence is clearly linear, and it is possible to obtain the activation energies for excimer formation and dissociation for the two compounds in water. This now allows us to obtain the activation energy values in water which were previously undetermined by the absence of the LTL slope in the Stevens-Ban plots of the two compounds. For compound $\mathbf{L 2}$, at the $\mathrm{pH}$ value considered $(\mathrm{pH}=2)$, both the excimer formation and dissociation rate constants are considerably more activated than with L1. However, because the difference in the activation values for excimer dissociation is much higher than the difference in the activation energy for excimer formation, the excimers of $\mathbf{L} \mathbf{2}$ are considerably more stable; that is, once they have formed, it is considerablly more difficult to dissociate them into excited and nonexcited monomer. In the whole temperature range, where $\alpha$ is low enough to allow the drawing of some conclusions, another interesting feature can be retrieved. In fact, despite the higher activation for excimer formation/dissociation of com- 

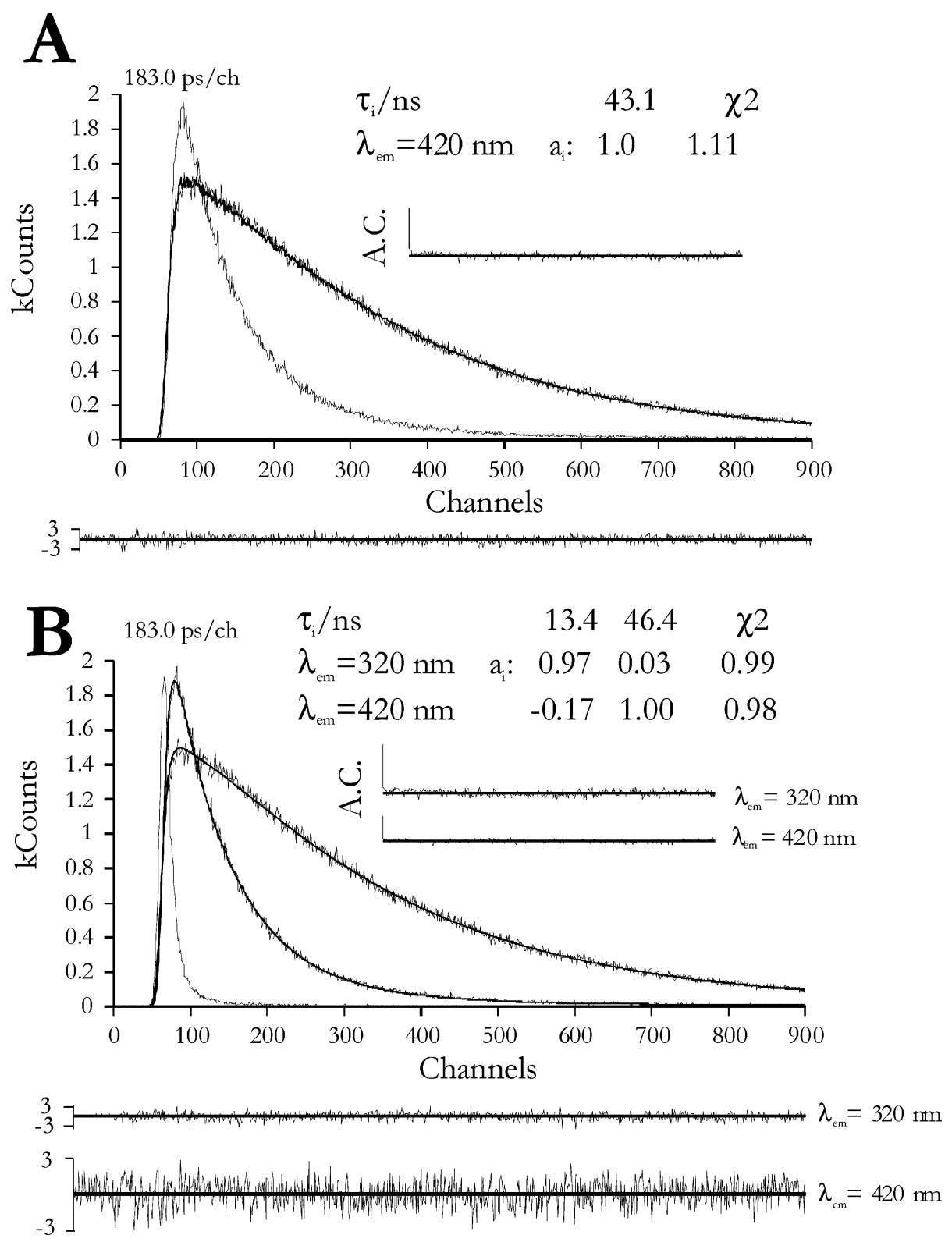

Figure 8. Fluorescence decays for compound $\mathbf{L 1}$ at $\mathrm{pH}=3$ and $20^{\circ} \mathrm{C}$ analyzed with (A) excimer decay deconvoluted with monomer decay (eq 14) and (B) global analysis of monomer and excimer decays (deconvolution of the monomer and excimer decays from the instrumental response profile).

pound L2, the rate constants have higher values; that is, the preexponential factors (of the Arrhenius equation) are considerably higher for compound $\mathbf{L} \mathbf{2}$ than they are for $\mathbf{L} \mathbf{1}$. The logical conclusion to be taken is that, with compound $\mathbf{L 2}$, the naphthalene chromophores have higher frequency of encounters than with L1; that is, with the former, we have a higher number of conformations where the terminal naphthyl groups are close enough to induce excimer formation.

Comparison between the activation energies for the excimer formation, obtained in the two solvents, revealed that in water values ca. three times larger than in ethanol were found. This means that the energetic barrier to overcome in water is much higher than in ethanol. This could be explained by the stronger hydrogen bonds established with the former solvent and the compound. In fact at acidic $\mathrm{pH}$ values, the $\mathrm{LH}_{6}$ species is largely predominant and the acidic aminic hydrogens of the two compounds are much more strongly connected with the solvent when this is water. However, it could also be understood by the presence (in ethanol) of an additional pathway to excimer formation, requiring less energy, e.g., the presence of a species (or particular conformation) closer in geometry to the excimer itself (a type of ground-state dimer not visible in water, see the next section below).

Fluorescence Decays in Ethanol and Ethanol:Water Mixtures. The analysis of the fluorescence decays of compound $\mathbf{L 1}$ in ethanol revealed the presence of an additional short lifetime component (see Table 4). Moreover, the absence of a rise-time at the excimer emission wavelength is particularly intriguing. Pure ethanol is obviously a media where we can have multiple species in equilibrium. As a consequence, species with similar lifetimes but different excited state concentrations (preexponential factors) can cancel each other's contribution and explain the absence of a visible rise time. To avoid this multiple number of species, we have performed a systematic study with acidified ethanol:water mixtures (water at $\mathrm{pH}=1$ ). At this $\mathrm{pH}$, in water (and presumably in ethanol), we should be only in the presence of the $\mathrm{LH}_{6}$ and excimer species (see Figure 2 ). However, as told in the beginning of this section, an additional lifetime appears whenever ethanol is present in the mixture. Short lifetime components (with lifetimes ranging from 


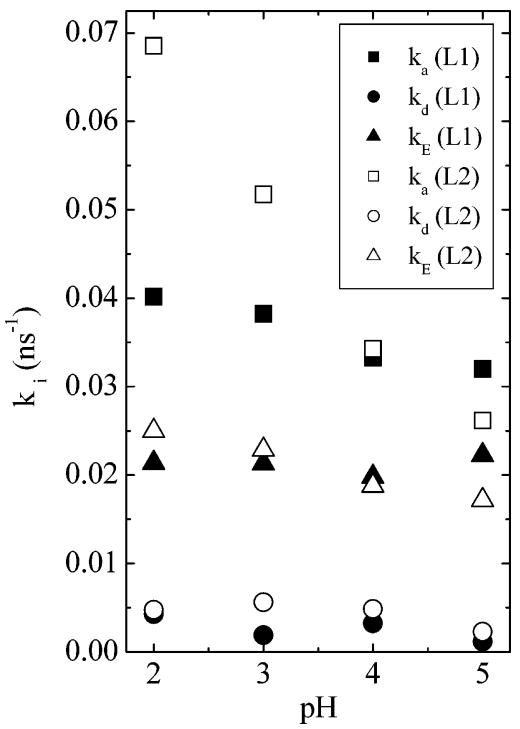

Figure 9. Rate constants dependence with $\mathrm{pH}$ for compounds $\mathbf{L 1}$ (closed symbols) and $\mathbf{L 2}$ (open symbols); $k_{\mathrm{a}}$ (squares), $k_{\mathrm{d}}$ (circles), and $k_{\mathrm{E}}$ (up triangles).
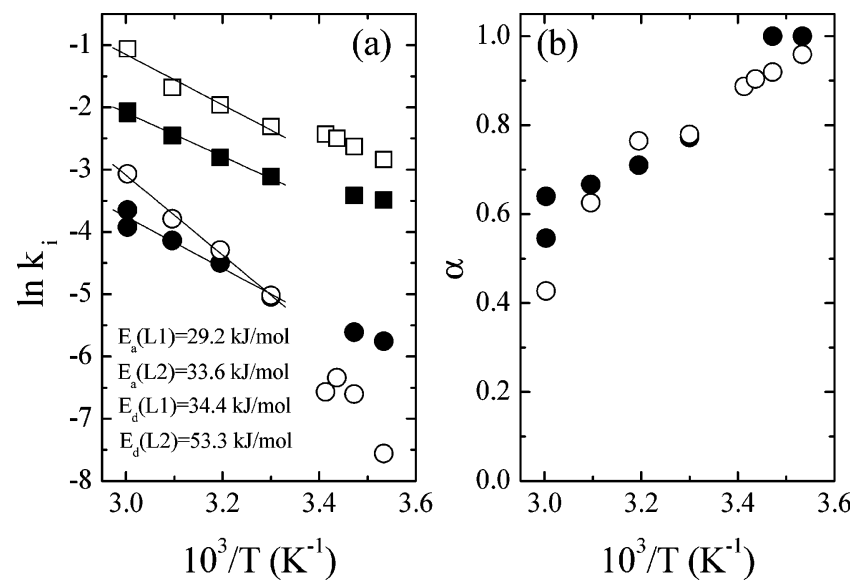

Figure 10. (a) Arrhenius plots of the rate constants for excimer formation, $k_{\mathrm{a}}$, squares, and excimer dissociation, $k_{\mathrm{d}}$, circles, for compounds $\mathbf{L 1}$ (closed symbols) and $\mathbf{L 2}$ (open symbols). (b) Temperature dependence of the fraction of preformed excimer, obtained from the sum of the preexponentials at 420 , for compounds $\mathbf{L 1}$ (closed circles) and $\mathbf{L 2}$ (open circles).

TABLE 4: Fluorescence Decays Parameters Obtained for Compound L1 in Ethanol:Water Mixtures ${ }^{a}$

\begin{tabular}{ccccccrcc}
\hline EtOH: $\mathrm{H}_{2} \mathrm{O}$ & $\lambda_{\mathrm{em}}$ & $\tau_{1}$ & $\tau_{2}$ & $\tau_{3}$ & $a_{\mathrm{i} 1}$ & \multicolumn{1}{c}{$a_{\mathrm{i} 2}$} & $a_{\mathrm{i} 3}$ & $\chi^{2}$ \\
\hline $0: 100$ & 320 & & 12.6 & 45 & & 0.981 & 0.019 & 1.55 \\
& 420 & & & & & -0.163 & 1.000 & 1.49 \\
$50: 50$ & 320 & 1.9 & 17.8 & 57.2 & 0.433 & 0.550 & 0.017 & 1.12 \\
& 420 & & & & 0.307 & -0.177 & 0.693 & 1.45 \\
& 460 & & & & 0.569 & -0.056 & 0.431 & 1.38 \\
$90: 10$ & 320 & 3.2 & 21.6 & 59.2 & 0.286 & 0.683 & 0.030 & 1.27 \\
& 420 & & & & 0.612 & -0.041 & 0.388 & 1.29 \\
$99: 1$ & 320 & 2.5 & 20.8 & 53.4 & 0.285 & 0.689 & 0.025 & 1.56 \\
& 420 & & & & 0.819 & 0.071 & 0.11 & 1.41 \\
$100: 0$ & 320 & 2.3 & 15.4 & 41.8 & 0.545 & 0.427 & 0.027 & 1.27 \\
& 420 & & & & 0.711 & 0.212 & 0.077 & 1.27
\end{tabular}

${ }^{a}$ The $\mathrm{pH}$ of water is 1.1 . The data were obtained by global analysis of the decays. Also presented are the chi-squared values for a better judgement of the quality of the fits. The excitation wavelength is 285 $\mathrm{nm}$.

2 to $3 \mathrm{~ns}$ ) were observed for pyrene-based compounds and have been attributed to a dimeric species that can deactivate or give rise, in the excited state, to excimer formation. ${ }^{48-50}$ The correct
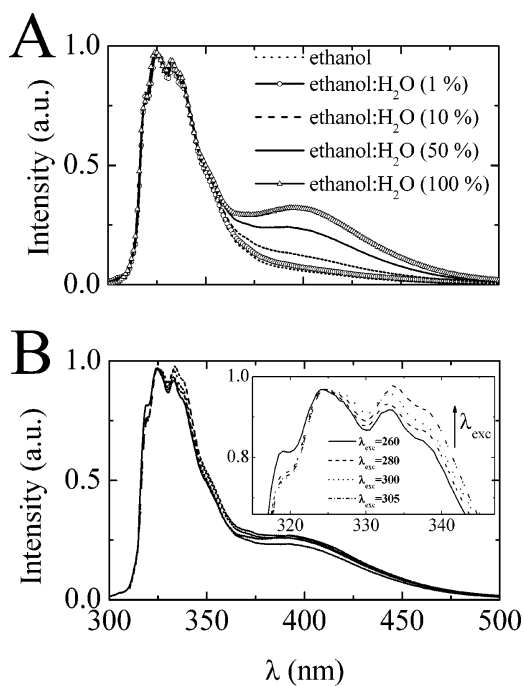

Figure 11. Fluorescence spectra of compound L1 in (A) different ethanol:water mixtures (water $\mathrm{pH}=1$ ) at $T=293 \mathrm{~K}$ and $(\mathrm{B})$ the ethanol:water mixture 50:50 obtained with different excitation wavelengths (normalized at $324 \mathrm{~nm}$ ). Shown as inset is the magnified view of the $300-350 \mathrm{~nm}$ range.

nature of this species is not yet fully understood, but it has been suggested that it results from the association of two, not totally overlapped, chromophores. ${ }^{48}$ In the case of the mentioned pyrene-based compounds, there is evidence for this emission to occur at $420 \mathrm{~nm}$ or in the monomer emission region. In the first case, it was suggested that the emitting dimer is probably in a conformational stage very close to the excimer (a situation of fast equilibrium between the dimer and the excimer). In the case of the dimer which emission overlaps with the monomer emission, this should again be in a fast equilibrium situation but now with the monomer and the excimer. In any case, the fluorescence emission spectra becomes different at the monomer region, and the decays now have an additional short lifetime component. ${ }^{48-50}$ Note that in the case of pyrene-based compounds the evidence in the emission spectra lies in the fact that the monomer emission band is highly resolved and consequently any change in the emission spectra is easily detected by comparison with the unaltered spectra. Although not so intensified as in the pyrene case, the naphthalene monomer emission band also presents vibronic resolution. An alteration of this progression can be viewed as evidence for dimer emission in the monomer region (see Figure 11B and discussion below).

We believe that a parallel situation is occurring with the present system and that this is highly influenced by the nature of the solvent. In Table 4, several observations merit a particular emphasis. First of all, note that the preexponential factor (associated to the short lifetime), at the $420 \mathrm{~nm}$ emission wavelength, increases with the amount of ethanol in the mixture (the exception is perhaps ethanol itself due to the existence of additional species) and the preexponential associated with the longer emission component (the excimer component) decreases at this same wavelength. If we observe the steady-state fluorescence spectra in these same mixtures (Figure 11A), we observe a gradual decrease of the excimer band with the increase in ethanol in the mixture. The observation of the steady-state (Figure 11A) and time-resolved (Table 4) shows that for the $100 \%$ water solution and for the 50:50 ethanol:water solution the $420 \mathrm{~nm}$ band is mainly due to the emission of the excimer but not to the dimer. From there on, the dimer gains a progressive "control" of the emission in that region as attested by the decrease in $a_{23}$ and increase in $a_{21}$ preexponential factors 


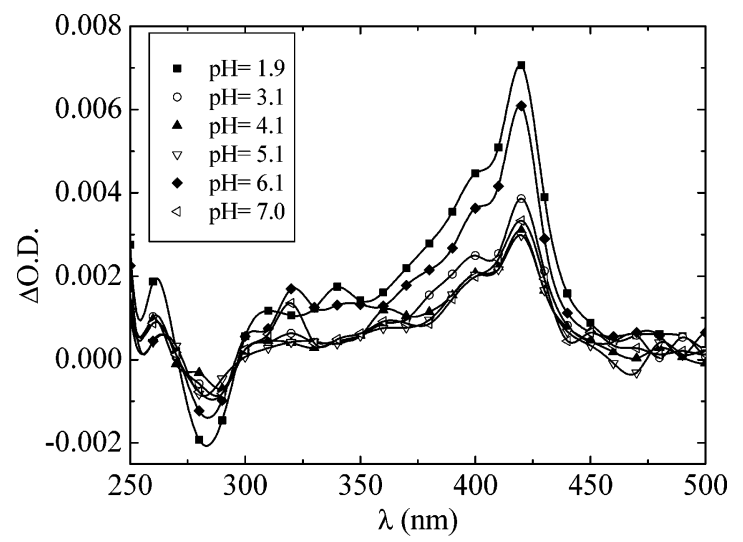

Figure 12. Transient triplet - triplet absorption spectra for compound L1 obtained at different $\mathrm{pH}$ values, $T=20^{\circ} \mathrm{C}$ and delay after flash is $2 \mu \mathrm{s}$.

TABLE 5: Intersystem Crossing Quantum Yields $\left(\phi_{\mathrm{T}}\right)$, Ground $\left(\epsilon_{\mathrm{S}}\right)$ and Triplet-Triplet $\left(\epsilon_{\mathrm{T}}\right)$ Extinction Coefficients, Lifetimes for Triplet Decay, and Quenching Rate Constants by Oxygen $\left(k_{\mathrm{ox}}\right)$ for Compound $\mathrm{L1}$ at Different pH Values and $T=20{ }^{\circ} \mathrm{C}$

\begin{tabular}{|c|c|c|c|c|c|}
\hline $\mathrm{pH}$ & $\phi_{\mathrm{T}}$ & $\begin{array}{c}\epsilon_{\mathrm{S}} / \\
\mathrm{M}^{-1} \mathrm{~cm}^{-1}\end{array}$ & $\begin{array}{c}\epsilon_{\mathrm{T}} / \\
\mathrm{M}^{-1} \mathrm{~cm}^{-1}\end{array}$ & $\tau_{\mathrm{T}} / \mu \mathrm{s}$ & $\begin{array}{c}k_{\mathrm{ox}} / \\
10^{8} \mathrm{~s}^{-1} \mathrm{M}^{-1}\end{array}$ \\
\hline 3.1 & 0.24 & 10430 & 46440 & 83 & 1.54 \\
\hline 4.1 & 0.21 & 10430 & 45790 & 87 & 1.75 \\
\hline 5.1 & 0.26 & 10430 & 35720 & 94 & 2.52 \\
\hline 8.7 & 0.19 & 10430 & 33630 & 153 & 0.702 \\
\hline
\end{tabular}

(see Table 4). The fact that at the emission wavelength of 320 $\mathrm{nm}$ there is a significant contribution of this short lifetime species, i.e., at the monomer emission wavelength, is presumably evidence for the emission, of the new dimer, in that region and that it must be in fast equilibrium with the monomer and the excimer. In fact, if we selectively excite in different regions of the $\mathbf{L} \mathbf{1}$ absorption band (naphthalene chromophore) and then normalize the spectra at $324 \mathrm{~nm}$, what we observe is a different vibrational progression in the monomer band (Figure 11B). Because the only factor that has been changed is the excitation wavelength, this shows that the dimer is emitting in the monomer region. Moreover, this component is highly predominant in the pure ethanol solution, with the excimer contribution $\left(a_{23}\right)$ being almost negligible.

The overall data in ethanol and ethanol:water mixtures suggests that the presence of this new dimer affects the dynamics and energetics of excimer formation in compound L1. In fact, the decrease in the $E_{\mathrm{a}}$ value, from water to ethanol (Table 2), suggests that the formation of this new species decreases the barrier height for excimer formation. This fact is understandable if we assume that the encounter of an excited chromophore with a nonexcited chromophore is already present even if it is not with the proper geometry for full overlap. In a way, the dimer acts as new route for excimer formation.

Triplet-Triplet Absorption. The possibility of intersystem crossing (ISC) acting as a new and competitive route with fluorescence deactivation was investigated in water at several $\mathrm{pH}$ values. The transient triplet-triplet absorption spectra for compound $\mathbf{L 1}$, obtained at different $\mathrm{pH}$ values is shown in Figure 12. Spectral and photophysical data are presented in Table 5. The signal was identified as a triplet because it decayed in the $\mu$ s region and was quenched by oxygen $\left(k_{\mathrm{ox}}\right)$ with a rate constant nearly identical to the diffusional limit. The constancy of $\phi_{\mathrm{T}}$ with $\mathrm{pH}$ ensures that the intersystem crossing process $\left(\mathrm{S}_{1} \sim \sim \mathrm{T}_{1}\right)$ is not truly competitive with fluorescence. The observed quenching with $\mathrm{pH}$, of the fluorescence emission for both compounds and in particular the monomer emission quenching, is therefore a consequence of the role promoted by the intramolecular electron transfer from the deprotonated amines to the excited naphthalene fluorophore. ${ }^{38}$

\section{Summary/Conclusions}

We have accomplished a complete spectroscopic and photophysical characterization of two new polyaminic derivatives possessing naphthalene as signaling units of the light induced molecular movements. It was shown that the central spacer unit, with different connections to the central benzene with the polyaminic chain, leads to small but significant differences in the photophysical behavior of the two compounds, namely in the rate of excimer formation at acidic $\mathrm{pH}$ values. Rate constants for the excimer formation, dissociation, and deactivation were obtained by time-resolved fluorescence data and by employing data obtained from the internal convolution procedure. Activation energy values for the excimer formation, obtained in water and ethanol, showed that these were higher in the former, probably due to a stronger hydrogen bond between the solvent and the compound. In ethanol and ethanol:water mixtures at acidic $\mathrm{pH}$ values, based on time-resolved data, a new species was identified. This new species acts as a catalyst, decreasing the activation energy for excimer formation. In the case of naphthalene based compounds, it is, to the best of our knowledge, the first time that evidence for such dimer is presented.

Acknowledgment. This work was supported in part by FCT Project 32442/99 (Portugal), PRAXIS/QUI/10137/98, HPRNCT-2000-00029 (EC), DGICYT Project BQU2000-1424 (Spain), the Spanish-Portuguese Program of Acciones Integradas No. E-38/02 and the European Community's Human Potencial Program under Contract HPRN-CT-2000-00029 [Molecular Level Devices and Machines]. C.L. acknowledges the financial support provided through the European Community's Human Potencial Program under Contract HPRN-CT-2000-00029 [Molecular Level Devices and Machines].

\section{Appendix}

According to Scheme 3, the excited-state concentration time dependence of the two species is given by the following set of differential equations given in matricial form by equation A.1:

$$
\frac{\mathrm{d}}{\mathrm{d} t}\left[\begin{array}{l}
M^{*} \\
E^{*}
\end{array}\right]\left[\begin{array}{ll}
-k_{\mathrm{X}} & \mathrm{k}_{\mathrm{d}} \\
\mathrm{k}_{\mathrm{a}} & -k_{\mathrm{Y}}
\end{array}\right]\left[\begin{array}{l}
M^{*} \\
E^{*}
\end{array}\right]
$$

where $\mathrm{M}^{*}$ and $\mathrm{E}^{*}$ are the concentrations of $\mathrm{M}$ and $\mathrm{E}$ in the excited state and $k_{\mathrm{X}}=k_{\mathrm{a}}+k_{\mathrm{M}}$ and $k_{\mathrm{Y}}=k_{\mathrm{E}}+k_{\mathrm{d}}$.

The integration of eq A.1 leads to

$$
\left[\begin{array}{l}
M^{*} \\
E^{*}
\end{array}\right]=\left[\begin{array}{ll}
a_{11} & a_{12} \\
a_{21} & a_{22}
\end{array}\right]\left[\begin{array}{l}
\mathrm{e}^{-\lambda_{1} t} \\
\mathrm{e}^{-\lambda_{2} t}
\end{array}\right]
$$

where the eigenvalues $\lambda_{i}$ are the reciprocal decay times and are related to the rate constants in Scheme 3 by the characteristic equation (eq A.3) $)^{51}$

$$
\left|\begin{array}{ll}
\lambda-k_{\mathrm{X}} & k_{\mathrm{d}} \\
k_{\mathrm{a}} & \lambda-k_{\mathrm{Y}}
\end{array}\right|=0
$$

whose solutions are given by eq A.4

$$
2 \lambda_{2,1}=k_{\mathrm{X}}+k_{\mathrm{Y}} \pm \sqrt{\left(k_{\mathrm{X}}-k_{\mathrm{Y}}\right)^{2}+4 k_{\mathrm{a}} k_{\mathrm{d}}}
$$


Through simple matricial operations we obtain eq A.5

$$
\left[\begin{array}{ll}
-k_{\mathrm{X}} & k_{\mathrm{d}} \\
k_{\mathrm{a}} & -k_{\mathrm{Y}}
\end{array}\right]=\left[\begin{array}{ll}
a_{11} & a_{12} \\
a_{21} & a_{22}
\end{array}\right] \cdot\left[\begin{array}{ll}
-\lambda_{1} & 0 \\
0 & -\lambda_{2}
\end{array}\right] \cdot\left[\begin{array}{ll}
a_{11} & a_{12} \\
a_{21} & a_{22}
\end{array}\right]^{-1}
$$

which relates the rate constants with the $\lambda_{i}$ values and the amplitudes obtained at the monomer and excimer decays.

However, according to Scheme 3, excimer formation is already present in the ground-state, and thus, the fraction of light exciting the ground-state molecules should be split in two different routes $(\alpha$ and $1-\alpha$ ). According to this scheme, the preexponential factors (which translate the excited-state concentration of the $\mathrm{M}^{*}$ and $\mathrm{E}^{*}$ species) are given by

$$
\begin{gathered}
a_{11}=\frac{\left(k_{\mathrm{X}}-\lambda_{2}\right)(1-\alpha)-\alpha k_{\mathrm{d}}}{\lambda_{1}-\lambda_{2}} \\
a_{12}=\frac{\left(\lambda_{1}-k_{\mathrm{X}}\right)(1-\alpha)+\alpha k_{\mathrm{d}}}{\lambda_{1}-\lambda_{2}} \\
a_{21}=\frac{\left[\left(k_{\mathrm{X}}-\lambda_{2}\right)(1-\alpha)-\alpha k_{\mathrm{d}}\right]\left(k_{\mathrm{X}}-\lambda_{1}\right)}{k_{\mathrm{d}}\left(\lambda_{1}-\lambda_{2}\right)} \\
a_{22}=\frac{\alpha k_{\mathrm{d}}\left(\lambda_{1}-\lambda_{2}\right)-\left[\left(k_{\mathrm{X}}-\lambda_{2}\right)(1-\alpha)-\alpha k_{\mathrm{d}}\right]\left(k_{\mathrm{X}}-\lambda_{1}\right)}{k_{\mathrm{d}}\left(\lambda_{1}-\lambda_{2}\right)}
\end{gathered}
$$

\section{References and Notes}

(1) Balzani, V.; Credi, A.; Venturi, M. ChemPhysChem 2003, 4, 49.

(2) Balzani, V.; Credi, A.; Venturi, M. Chem.-Eur. J. 2002, 8, 5524

(3) Ballardini, R.; Balzani, V.; Clemente-Leon, M.; Credi, A.; Gandolfi, M. T.; Ishow, E.; Perkins, J.; Stoddart, J. F.; Tseng, H. R.; Wenger, S. J. Am. Chem. Soc. 2002, 124, 12786.

(4) Balzani, V.; Credi, A.; Venturi, M. Proc. Natl. Acad. Sci. U.S.A. 2002, $99,4814$.

(5) de Silva, A. P.; Gunaratne, H. Q. N.; McCoy, C. P. J. Am. Chem. Soc. 1997, 119, 7891

(6) de Silva, A. P.; Gunaratne, H. Q. N.; Gunnlaugsson, T.; Huxley, A. J. M.; McCoy, C. P.; Rademacher, J. T.; Rice, T. E. Chem. Rev. 1997 97, 1515. 1759 .

(7) de Silva, A. P.; Gunnlaugsson, T.; Rice, T. E. Analyst 1996, 121 ,

(8) de Silva, A. P.; Gunnlaugsson, T.; McCoy, C. P. J. Chem. Educ. 1997, 74, 53.

(9) Albelda, M. T.; García-España, E.; Gil, L.; Lima, J. C.; Lodeiro, C.; Seixas de Melo, J.; Melo, M. J.; Parola, A. J.; Pina, F.; Soriano, C. J. Phys. Chem. B 2003, 107, 6573.

(10) Seixas de Melo, J.; Albelda, M. T.; Diaz, P.; García-España, E.; Lodeiro, C.; Alves, S.; Lima, J. C.; Pina, F.; Soriano, C. J. Chem. Soc., Perkin Trans. 2 2002, 991.

(11) Lodeiro, C.; Parola, A. J.; Pina, F.; Bazzicalupi, C.; Bencini, A.; Bianchi, A.; Giorgi, C.; Masotti, A.; Valtancoli, B. Inorg. Chem. 2001, 40, 2968.

(12) Albelda, M. T.; Diaz, P.; García-España, E.; Lima, J. C.; Lodeiro, C.; Seixas de Melo, J.; Parola, A. J.; Pina, F.; Soriano, C. Chem. Phys. Lett. 2002, 353, 63.

(13) Bencini, A.; Bianchi, A.; Giorgi, C.; Romagnoli, E.; Lodeiro, C.; Saint-Maurice, A.; Pina, F.; Valtancoli, B. Supramol. Chem. 2001, 13, 277.

(14) Alves, S.; Pina, F.; Albelda, M. T.; García-España, E.; Soriano, C.; Luis, S. V. Eur. J. Inorg. Chem. 2001, 405.
(15) Bencini, A.; Bernardo, M. A.; Bianchi, A.; Fusi, V.; Giorgi, C.; Pina, F.; Valtancoli, B. Eur. J. Inorg. Chem. 1999, 1911.

(16) Pina, F.; Melo, M. J.; Bernardo, M. A.; Luis, S. V.; García-España, E. J. Photochem. Photobiol. A: Chem. 1999, 126, 65.

(17) Bazzicalupi, C.; Bencini, A.; Bianchi, A.; Giorgi, C.; Fusi, V.; Valtancoli, B.; Bernardo, M. A.; Pina, F. Inorg. Chem. 1999, 38, 3806.

(18) Pina, F.; Parola, A. J. Coord. Chem. Rev. 1999, 186, 149.

(19) Bernardo, M. A.; Pina, F.; Escuder, B.; García-España, E.; GodinoSalido, M. L.; LaTorre, J.; Luis, S. V.; Ramirez, J. A.; Soriano, C. J. Chem. Soc., Dalton Trans. 1999, 915.

(20) Bernardo, M. A.; Pina, F.; García-España, E.; LaTorre, J.; Luis, S. V.; Llinares, J. M.; Ramirez, J. A.; Soriano, C. Inorg. Chem. 1998, 37, 3935 .

(21) Parola, A. J.; Pina, F.; Manfrin, M. F.; Moggi, L. J. Chem. Soc., Dalton Trans. 1998, 1005.

(22) Bernardo, M. A.; Alves, S.; Pina, F.; Seixas de Melo, J.; Albelda, M. T.; García-España, E.; Llinares, J. M.; Soriano, C.; Luis, S. V. Supramol. Chem. 2001, 13, 435 .

(23) Albelda, M. T.; Bernardo, M. A.; Diaz, P.; García-España, E.; Seixas de Melo, J.; Pina, F.; Soriano, C.; Santiago, V. L. E. Chem. Commun. 2001, 1520.

(24) Bazzicalupi, C.; Bencini, A.; Berni, E.; Bianchi, A.; Giorgi, C.; Fusi, V.; Valtancoli, B.; Lodeiro, C.; Roque, A.; Pina, F. Inorg. Chem. 2001, 40, 6172 .

(25) García-España, E.; Ballester, M. J.; Lloret, F.; Moratal, J. M.; Faus, J.; Bianchi, A. J. Chem. Soc., Dalton Trans. 1998, 101.

(26) Fontanelli, M.; Micheloni, M. Proceedings of the I Spanish-Italian Congress on Thermodynamics of Metal Complexes; Diputación de Castellón: Spain, 1990.

(27) Gran, G. Analyst 1952, 77, 881.

(28) Rossotti, F. J.; Rossotti, H. J. J. Chem. Educ. 1965, 42, 375.

(29) Sabatini, A.; Vacca, A.; Gans, A. Coord. Chem. Rev. 1992, 120 389.

(30) Murov, S.; Charmichael, I.; Hug, G. L. Handbook of Photochemistry; M. Dekker Inc.: New York, 1993.

(31) Seixas de Melo, J.; Fernandes, P. F. J. Mol. Struct. 2001, 565566,69 .

(32) Stricker, G.; Subramaniam, V.; Seidel, C. A. M.; Volkmer, A. J. Phys. Chem. B 1999, 103, 8612

(33) Seixas de Melo, J.; Silva, L. M.; Kuroda, M. J. Chem. Phys. 2001, 115,5625

(34) Carmichael, I.; Hug, G. L. J. Phys. Chem. Ref. Data 1986, 15, 1.

(35) Kumar, C. V.; Qin, L.; Das, P. K. J. Chem. Soc., Faraday Trans.

2 1984, 80, 783.

(36) Menif, R.; Martell, A. E.; Squatrito, P. J.; Clearfield, A. Inorg. Chem. 1990, 29, 4723 .

(37) Basallote, M. G.; Durán, J.; Fernández-trujillo, M. J.; Máñez, M. A.; Quirós, M.; Salas, J. M. Polyhedron 2001, 20, 297.

(38) Pina, F.; Lima, J. C.; Lodeiro, C.; Seixas de Melo, J.; Diaz, P.; Albelda, M. T.; García-España, E. J. Phys. Chem. A 2002, 106, 8207.

(39) Birks, J. B. Photophysics of Aromatic Molecules; Wiley: London, 1970

(40) Stevens, B.; Ban, M. I. Trans. Faraday Soc. 1964, 60, 1515

(41) Schillen, K.; Anghel, D. F.; Miguel, M. D.; Lindman, B. Langmuir 2000, 16, 10528 .

(42) Winnik, F. M. Chem. Rev. 1993, 93, 587

(43) Winnik, M. A.; Bystryak, S. M.; Liu, Z. Q.; Siddiqui, J. Macromolecules 1998, 31, 6855 .

(44) Ezzell, S. A.; Hoyle, C. E.; Creed, D.; McCormick, C. L. Macromolecules 1992, 25, 1887.

(45) Macanita, A. L.; Horta, A.; Pierola, I. F. Macromolecules 1994 27,958

(46) Conte, J. C.; Martinho, J. M. G. Chem. Phys. Lett. 1987, 134, 350

(47) Vigil, M. R.; Renamayor, C. S.; Pierola, I.; Lima, J. C.; Melo, E. C.; Macanita, A. L. Chem. Phys. Lett. 1998, 287, 379

(48) Seixas de Melo, J.; Costa, T.; Miguel, M. d. G.; Lindman, B.; Schillén, K. J. Phys. Chem. B 2003, 107, 12605.

(49) Ilharco, L. M.; Martinho, J. M. G. Langmuir 1999, 15, 7490

(50) Picarra, S.; Relogio, P.; Afonso, C. A. M.; Martinho, J. M. G.; Farinha, J. P. S. Macromolecules 2003, 36, 8119.

(51) Boyce, W. E.; DiPrima, R. C. Elementary Differential Equations and Boundary Value Problems, 4th ed.; John Wiley \& Sons: New York, 1986. 